\title{
Resale Price Maintenance and Collusion
}

\author{
Bruno Jullien \\ Patrick Rey \\ GREMAQ and IDEI, Université des Sciences Sociales Toulouse 1
}

May 9, 2000 


\begin{abstract}
The paper revisits the conventional wisdom according to which vertical restrictions on retail prices help upstream firms to collude. We analyze the scope for collusion with and without resale price maintenance (RPM) when retailers observe local shocks on demand or retail costs.

In the absence of RPM, retail prices react to retailers' information and deviations from collusive behavior are thus difficult to detect. By eliminating retail price flexibility, RPM facilitates the detection of deviations but reduces profits and increases the short-run gains from a deviation. Overall, RPM can facilitate collusion and it reduces total welfare whenever firms choose to adopt it.
\end{abstract}




\section{Non Technical Summary}

The paper revisits the conventional wisdom according to which vertical restrictions on retail prices help upstream firms to collude.

Although competition authorities' attitude towards vertical restraints varies substantially across countries, price restrictions are often treated less favorably than non-price restrictions such as exclusive territories, selective distribution, etc. While there are some variations according to the nature of the price restriction, Resale Price Maintenance $(R P M)$ is for example generally viewed as per se illegal or, at the very least, as most probably undesirable.

This consensus against $R P M$ contrasts with the economic analysis of vertical restraints, which shows that both price and non-price vertical restrictions may either improve or harm economic efficiency - and often provide alternative ways to achieve the same objective. Furthermore, most of the arguments made by the courts to justify their tolerant attitude towards non-price restrictions would apply as well to $R P M$. There is, however, one argument made in practice against $R P M$, which is that it could facilitate horizontal agreements.

The present paper explores this argument in more detail and starts from the idea that, under $R P M$, retail prices are centrally set by the manufacturer and thus do not fully adjust to local variations on retail costs or demand; as a result, retail prices are more uniform under $R P M$, and deviations from a tacit agreement are thus more easily detected; it follows that $R P M$, while being less efficient since it generates less flexible prices, can be adopted to facilitate interbrand collusion.

In our model, long-lived producers sell to short-sighted retailers. In each period, each producer signs an exclusive contract with a retailer. Demand is stochastic, and retailers receive private information on their demand after contracting but before the good is delivered to the market. Retail prices, but not wholesale prices, are observable by competitors. We derive the most profitable collusive equilibrium in two cases: in the first case, vertical contracts are restricted to franchise contracts while in the second case, producers can moreover control the retail price $(R P M)$. When $R P M$ is banned, retail prices react to retailers' information, which makes it harder to detect a deviation from collusive behavior. By eliminating retailers' pricing discretion, $R P M$ facilitates the detection of such deviations. On the other hand, $R P M$ rigidifies retail prices and, ceteris paribus, reduces profits; it thereby raises the short-run incentives to deviate. We characterize the situations where $R P M$ effectively increases collusive equilibrium profits. 
We also show that, when collusion is a serious concern, $R P M$ reduces welfare whenever it allows firms to increase their profits. The key point is that while price rigidity facilitates the detection of a deviation for a collusive agreement, it reduces the profitability of the collusive outcome. Thus, colluding firms will impose $R P M$ only when the increase in the collusive price is high enough to compensate them from the negative impact on profits. This effect is strong enough to offset the potential welfare benefits that $R P M$ may generate. As a result welfare is reduced when $R P M$ is allowed. This result is reinforced by the fact that $R P M$ may also increase the ability of firms to punish a participant after a deviation.

We also compare $R P M$ with alternative vertical restraints and show that, compared with non-price restrictions, $R P M$ provides firms with a better instrument to detect deviations from collusion. 


\section{Introduction}

Although competition authorities' attitude towards vertical restraints varies substantially across countries, price restrictions are often treated less favorably than non-price restrictions such as exclusive territories, selective distribution, etc. While there are some variations according to the nature of the price restriction (advertised or recommended prices, price floors, price ceilings, etc.), Resale Price Maintenance (RPM, whereby retail prices are set by manufacturers rather than by distributors) is for example generally viewed as per se illegal or, at the very least, as most probably undesirable. ${ }^{1}$

This consensus against RPM contrasts with the economic analysis of vertical restraints, which shows that both price and non-price vertical restrictions may either improve or harm economic efficiency - and often provide alternative ways to achieve the same objective. Furthermore, most of the arguments made by the courts to justify their tolerant attitude towards non-price restrictions would apply as well to RPM. For example, in GTE Sylvania, the US Supreme Court mainly gives two arguments to abandon the per se illegality of exclusive territories: a) non-price vertical restraints improve the efficiency of supply; b) non-price restrictions stimulate interbrand competition, while price restrictions are more likely to reduce it. It is interesting to review those two lines of arguments in the light of the economic literature on RPM and exclusive territories.

- Efficient supply of goods and services

The Supreme Court summarized its argument as follows:

"Established manufacturers can use [vertical restrictions] to induce retailers to engage in promotional activities or to provide service and repair facilities necessary to the efficient marketing of their products. The availability and quality of such services affect a manufacturer's goodwill and the competitiveness of his product. Because of market imperfections such as the so-called "free-rider" effect, these services might not be provided by retailers in a purely competitive situation, despite the fact that each retailer's benefit would be greater if all provided the services than if none did". ${ }^{2}$

This argument applies to RPM as well: by eliminating intrabrand competition on prices and guaranteeing a minimal retail margin, RPM actually

\footnotetext{
${ }^{1}$ In France, for example, price floors are per se illegal under article 34 of the 1986 Ordinance; RPM (including price ceilings) can also constitute a restriction of competition under article 7 as well as an abuse of economic dependance under article 8 of the same Ordinance. For a broad overview of the attitude towards price and non-price restrictions, see OECD (1994).

${ }^{2} 433$ U.S. (1977) at 55.
} 
stimulates intrabrand competition for services and induce distributors to supply better retail services. ${ }^{3}$ Furthermore, both price and non-price restrictions may improve efficiency but also raise profits at the expense of consumer surplus and total welfare. ${ }^{4}$

- Impact on interbrand competition

The Supreme Court also mentioned the "redeeming virtues" of vertical restrictions on interbrand competition:

"Vertical restrictions promote inter-brand competition by allowing the manufacturer to achieve certain efficiencies in the distribution of his products. These "redeeming virtues" are implicit in every decision sustaining vertical restrictions under the rule of reason. Economists have identified a number of ways in which manufacturers can use such restrictions to compete more effectively against other manufacturers. For example, new manufacturers and manufacturers entering new markets can use the restrictions in order to induce competent and aggressive retailers to make the kind of investment of capital and labor that is often required in the distribution of products unknown to the consumers". ${ }^{5}$

Economic analysis indeed suggests that vertical restraints may encourage entry and thus promote interbrand competition, e.g. by allowing greater efficiency. ${ }^{6}$ But there again, the argument is not limited to non-price verti-

${ }^{3}$ The Court actually almost recognized later in Monsanto (465 U.S. 752 (1984) at $762-$ 3) that price restrictions may constitute a better tool for improving supply efficiency: "It is precisely in cases in which the manufacturer attempts to further a particular marketing strategy by means of agreements on often costly non-price restrictions that it will have the most interest in the distributors' resale prices. The manufacturer often will want to ensure that its distributors earn sufficient profit to pay for programs such as hiring and training additional salesmen or demonstrating the technical features of the products, and will want to see that "free-riders" do not interfere".

${ }^{4}$ The best quality/price ratio, for example, is not the same for firms, who focus on demand and thus on their marginal customers, and for customers as a whole, including infra-marginal ones -see Spence (1975); therefore, allowing firms to improve vertical coordination may either benefit or harm consumers and total welfare -see Caillaud-Rey (1987) and Besanko-Perry (1997). Rey-Tirole (1986) offers an overview of the relative merits of price and non-price restrictions in improving vertical coordination between a manufacturer and its retailers.

Vertical restraints can also help producers to better exploit their market power (at the detriment of consumers and of economic efficiency), by limiting the scope for opportunistic behavior vis-à-vis their retailers; however, both exclusive territories and price control can be used to that effect -see O'Brien-Shaffer (1992).

${ }^{5} 433$ U.S. (1977) at 54-55.

${ }^{6}$ Vertical restraints may also attract more entrants in the long run by reducing competition in the short-run. This line of argument needs however to be qualified, since the trade-off between ex ante and ex post competition often generates ambiguous results. 
cal restrictions: price restrictions, too, can increase the profitability of the relationship between manufacturers and distributors.

There is also an abundant literature on the adverse impact of vertical restraints on interbrand competition. Many effects rely on the idea of strategic delegation, where manufacturers give more freedom to their retailers in order to commit themselves to respond more "appropriately" to their rivals' pricing strategies; in that respect, RPM goes the wrong way since it reduces the retailers' freedom of action. In contrast, granting exclusive territories gives more freedom to retailers, and can thus be used strategically by producers to reduce interbrand as well as intrabrand competition. ${ }^{7}$ Vertical restraints can also be used to deter entry of potentially more efficient rivals. ${ }^{8}$ But there again, the type of restraints that can serve strategic purposes are not price restrictions but exclusivity restrictions or restrictions that give more freedom to the distributors in the choice of retail prices. For example, assigning exclusive territories makes retailers more aggressive in the case of entry and might thus be used to deter local entry, which would instead be encouraged if RPM limited incumbent retailers' ability to respond.

Overall, the economic analysis thus does not appear to call for a less tolerant attitude towards price restrictions ${ }^{9}$ (the last line of argument even suggests instead to be less permissive towards non-price restrictions). There is, however, one last argument made in practice against RPM, which is that it could facilitate horizontal agreements. For example, in Business Electronics, the Supreme Court repeated its previous statement to justify the per se illegality of RPM:

"Our opinion in GTE Sylvania noted a significant distinction between vertical non-price and vertical price restraints. That is, there was support for the proposition that vertical price restraints reduce inter-brand price competition because they "facilitate cartelizing"... The authorities cited by the Court suggested how vertical price agreements might assist horizontal price fixing at the manufacturer level (by reducing the manufacturer's incentive to cheat on a cartel, since its retailers could not pass on lower prices to con-

\footnotetext{
${ }^{7}$ See for example Rey-Stiglitz (1988, 1995). This argument has recently been empirically tested by Slade (1998) in the context of a change of regulation in the UK beer industry.

${ }^{8}$ For example, long-term exclusive dealing contracts can raise entry barriers - see Aghion-Bolton (1987) and Hart-Tirole (1990). For a review of the literature on market foreclosure, see Rey-Tirole (1996). Comanor-Rey (1998) shows how well-established distributors can block the entry of more efficient rivals and discusses in this light the recent action of the Federal Trade Commission against TOY R'US.

${ }^{9}$ The Supreme Court later recognized this issue in Business Electronics, where it mentions the difficulty of defining a clear dividing line between per se illegal price restraints and non-price vertical restraints to be judged under the rule of reason, given that both affected retail prices. See 485 U.S. 717 (1988) at 727-728.
} 
sumers) or might be used to organize cartels at the retailer level. Similar support for the cartel-facilitating effect of vertical non-price restraints was and remains lacking". ${ }^{10}$

The Court's argument that "vertical price agreements" can facilitate collusion by reducing the incentive of a manufacturer to cheat on a cartel by lowering wholesale price has not been formalized and seems to rely on the assumption that the manufacturer can undertake not to modify the retail price set by the distributor - e.g., the contract makes the renegotiation of retail prices more difficult or costly than that of wholesale prices. ${ }^{11}$

The present paper explores this argument in more detail and starts from the idea that, under RPM, retail prices are centrally set by the manufacturer and thus do not fully adjust to local variations on retail costs or demand; as a result, retail prices are more uniform under RPM, and deviations from a tacit agreement are thus more easily detected; it follows that RPM, while being less efficient since it generates less flexible prices, can be adopted to facilitate interbrand collusion. ${ }^{12}$

In our model, long-lived producers sell to short-sighted retailers. In each period, each producer signs an exclusive contract with a retailer. Demand is stochastic, and retailers receive private information on their demand after contracting but before the good is delivered to the market. Retail prices, but not wholesale prices, are observable by competitors. We derive the most profitable collusive equilibrium in two cases: in the first case, vertical contracts are restricted to franchise contracts while in the second case, producers can moreover control the retail price (RPM). When RPM is banned, retail prices react to retailers' information, which makes it harder to detect a deviation from collusive behavior. By eliminating retailers' pricing discretion, RPM facilitates the detection of such deviations. On the other hand, RPM rigidifies retail prices and, ceteris paribus, reduces profits; it thereby raises the short-run incentives to deviate. We characterize the situations where RPM effectively increases collusive equilibrium profits and identify conditions under which RPM reduces welfare whenever it allows firms to increase their profits.

\footnotetext{
${ }^{10} 485$ U.S. 717 (1988) at 725-6. The argument that RPM reduces competition and efficiency when it serves merely to sustain a retail cartel is well-known, but exclusive territories would achieve the same aim.

${ }^{11}$ A manufacturer could otherwise "cheat" on the cartel agreement by modifying both the retail price and the wholesale price at the same time - RPM might actually make such deviation more appealing, by ensuring that the cut in wholesale price is not partially appropriated by retailers.

${ }^{12}$ Rey and Vergé (1999) analyze this issue from a different perspective and show that, when producers distribute their goods through the same competing distributors, RPM can eliminate any scope for effective competition even in the absence of repeated interaction.
} 
While the role of the information transmitted through the observed market outcomes is well-known since Green-Porter (1984) and Abreu-PearceStachetti (1986), to our knowledge this is the first attempt to analyze price restrictions as facilitating practices for collusion along these lines. The closest related work is the recent analysis of price rigidity by Athey-BagwellSancharico (1998), who analyze the collusive equilibria under Bertrand competition between firms having private information on their cost. ${ }^{13}$ Their model involves no vertical relationship but incomplete information. They focus on patient firms and thus rely on a folk theorem; in this context, the main issue is incentive compatibility on the equilibrium path: since costs are private information, a firm can pretend it has a low cost and adopt the corresponding equilibrium price. It is shown that for sufficiently high discount factors the best collusive equilibrium may involve a constant price, with no revelation of the costs. Our result is different in several respects. In their model, price variability is created by producers adjusting to their cost, while in our model it is due to distributors' behavior. The reduced form of the game played by producers in our model is similar to a collusion game with noisy observations in which $R P M$ allows to reduce the noise. Second, we do not rely on folk theorems: ${ }^{14}$ in our model sufficiently patient firms would actually achieve cartel profits without using RPM. One can thus view the two arguments as complementary explanations of the effect of price rigidity on collusion.

The paper is organized as follows. The next section describes the basic model, where producers distribute their goods through retailers who face local shocks on the demand, and defines useful benchmarks (competitive and monopoly prices). Section 3 analyses the scope for collusion in this setup, with and without $R P M$; the following two sections then focus on two ways in which $R P M$ can facilitate collusion: it can help detecting deviations from the collusive agreement (section 4) and it can also allow the firms to sustain harsher punishments when deviations are detected (section 5). Section 6 draws the policy implications. Section 7 shows that the analysis is robust to alternative assumptions on the nature of local shocks (retail cost uncertainty versus demand uncertainty), while section 8 briefly discusses how it would extend to the case where the type of contract ( $R P M$ or not) is itself not observed by rivals. Lastly, section 9 compares $R P M$ with alternative vertical restraints and shows that $R P M$ is generally in better position to help firms to detect deviations from a collusive path.

\footnotetext{
${ }^{13}$ Athey-Bagwell (1998) explores the scope for communication in this context.

${ }^{14}$ We build on Abreu (1986) and Abreu-Pearce-Stachetti (1990).
} 


\section{The basic model}

Two manufacturers, 1 and 2, produce differentiated goods with stochastic demand

$$
D_{i}\left(p_{i}, p_{j}\right)=d+\varepsilon_{i}-p_{i}+\sigma p_{j}, i \neq j=1,2,
$$

where $p_{i}$ is the retail price of manufacturer $i$ 's good and the demand shocks $\varepsilon_{1}$ and $\varepsilon_{2}$ are independently and uniformly distributed on the interval $[-\bar{\varepsilon}, \bar{\varepsilon}]$. Production and retail costs are normalized to 0 , and manufacturers face a fixed cost $k$. Manufacturers have an infinite life-time horizon and the same discount factor $\delta$. In each period, each manufacturer contracts with one retailer that lives only for one period (alternatively, manufacturers can only commit to spot distribution contracts). All parties are risk neutral and have a zero reservation utility level.

\subsection{The stage game}

At the contracting stage, the shocks $\varepsilon_{1}$ and $\varepsilon_{2}$ are unknown to all parties and manufacturers have all the bargaining power. Then, $\varepsilon_{i}$ is observed by retailer $i$ but not by the manufacturers nor the other retailer.

We shall contrast two situations: in the absence of $R P M$, each manufacturer $i$ offers a franchise contract, consisting of a franchise fee $A_{i}$ and a wholesale price $w_{i}$; under $R P M$, it can moreover set the retail price $p_{i} \cdot{ }^{15}$ Retail prices are publicly observed, whereas franchise fees and wholesale prices are not. For simplicity, we will however assume that the nature of contract ( $R P M$ or not) signed by one manufacturer is observed by its competitor at the end of the period - it may indeed be much easier for a competitor to observe the nature of a contract than its precise terms. We discuss in section 8 the case where the nature of the contract is not observed.

The timing of the stage game is thus as follows:

- first, each manufacturer $i$ secretly offers a contract, of the form $\left(A_{i}, w_{i}\right)$ or $\left(A_{i}, w_{i}, p_{i}\right)$, to a retailer, who accepts it or not;

- second, each retailer $i$ observes $\varepsilon_{i}$ and, if it has accepted the contract, sets the retail price $p_{i}$ (at the level chosen by the manufacturer under $R P M$ );

- third, demands and profits are realized; each manufacturer further observes the retail prices and the nature of the contract signed by its competitor.

\footnotetext{
${ }^{15}$ We focus on "pure" RPM contracts under which the retail price, being set by the manufacturer, is independent of $\varepsilon_{i}$. Also, we rule out contracts contingent on the competitor's price, since this would introduce explicit horizontal agreements that are per se illegal.
} 


\subsection{Benchmarks: Static equilibrium and collusion}

Suppose that the above game is played only once, and consider first the case where manufacturers are restricted to franchise contracts. If retailer $i$ accepts the contract $\left(A_{i}, w_{i}\right)$ then, denoting by $p_{j}^{e}$ the expected value of the rival's retail price, retailer $i$ will set its own retail price to (using the linearity of the profit function with respect to the rival's price, and the independence of the distribution of the two demand shocks)

$$
p_{i}=\arg \max _{p}\left(p-w_{i}\right)\left(d+\varepsilon_{i}-p+\sigma p_{j}^{e}\right)-A_{i}=\frac{d+\varepsilon_{i}+w_{i}+\sigma p_{j}^{e}}{2} .
$$

Denoting by $p_{i}^{e}$ the expected retail price of this retailer, (1) can be rewritten as

$$
p_{i}=p_{i}^{e}+\frac{\varepsilon_{i}}{2}
$$

where

$$
p_{i}^{e}=\frac{d+w_{i}+\sigma p_{j}^{e}}{2}
$$

Therefore, given the expected retail price for the rival good, $p_{j}^{e}$, by setting the wholesale price $w_{i}$ at the appropriate level manufacturer $i$ can perfectly control the expected price of its own product, $p_{i}^{e}$, but cannot control the flexibility of this price, which always "half responds" to the shock $\varepsilon_{i}$. For the sake of presentation, whenever there is no ambiguity we will say that the manufacturer "chooses the expected retail price $p_{i}^{e}$ " rather than the wholesale price $w_{i}$. Note that the manufacturer can recover the retailer's profit through the franchise fee, so that choosing $p_{i}^{e}$ yields an expected profit given by

$E\left[\left(p_{i}^{e}+\frac{\varepsilon_{i}}{2}\right)\left(d+\varepsilon_{i}-\left(p_{i}^{e}+\frac{\varepsilon_{i}}{2}\right)+\sigma p_{j}^{e}\right)\right]-k=p_{i}^{e}\left(d-p_{i}^{e}+\sigma p_{j}^{e}\right)+v(\bar{\varepsilon})-k$

where

$$
v(\bar{\varepsilon}) \equiv \frac{\bar{\varepsilon}^{2}}{12}
$$

denotes the variance of the retail prices.

Consider now the Nash equilibrium of this game. Since the contract offered to a retailer is not observed by the rival, it cannot influence the rival's retail price. Therefore, taking as given the expected value $p_{j}^{e}$ of the rival's equilibrium retail price, producer $i$ will choose $p_{i}^{e}$ so as to maximize 
(4), which is achieved for $p_{i}^{e}=\left(d+\sigma p_{j}^{e}\right) / 2$ by setting $w_{i}$ to zero. This is an illustration of a well-known principle: since the contract does not affect the rival's behavior, it is optimal to "sell the technology" to the retailer by charging a wholesale price equal to marginal cost, here zero; being the residual claimant, the retailer then sets its retail price so as to maximize the aggregate profits of the vertical structure, which the producer can appropriate through the franchise fee.

In equilibrium, both producers set their wholesale price to zero $\left(w_{1}=\right.$ $w_{2}=0$ ) and, solving (3), the expected prices $p_{1}^{e}$ and $p_{2}^{e}$ are therefore given by

$$
p_{1}^{e}=p_{2}^{e}=p^{N} \equiv \frac{d}{2-\sigma}
$$

Defining

$$
\pi\left(p_{i}, p_{j}\right) \equiv p_{i}\left(d-p_{i}+\sigma p_{j}\right)
$$

and

$$
\Pi(p) \equiv \pi(p, p)=p(d-(1-\sigma) p)
$$

each producer's expected Nash equilibrium profit is equal to $\Pi\left(p^{N}\right)+v(\bar{\varepsilon})-k$. In what follows we assume that Nash equilibrium profits are non-negative:

$$
k \leq \Pi\left(p^{N}\right)+v(\bar{\varepsilon}) .
$$

Suppose now that the two manufacturers can collude and both jointly determine their franchise contracts and make them publicly observed by both retailers. For given wholesale prices $w_{1}$ and $w_{2}$, the retail price equilibrium would still be governed by (1); retail prices would thus still satisfy (2) and (3), and expected retail prices would be determined by wholesale prices:

$$
p_{i}^{e}=\frac{1}{2-\sigma}\left(d+\frac{2 w_{i}+\sigma w_{j}}{2+\sigma}\right) .
$$

The manufacturers would therefore choose expected prices $p_{1}^{e}$ and $p_{2}^{e}$ that maximize

$$
\begin{gathered}
E_{\varepsilon_{1}}\left[\left(p_{1}^{e}+\frac{\varepsilon_{1}}{2}\right)\left(d+\frac{\varepsilon_{1}}{2}-p_{1}^{e}+\sigma p_{2}^{e}\right)\right]+E_{\varepsilon_{2}}\left[\left(p_{2}^{e}+\frac{\varepsilon_{2}}{2}\right)\left(d+\frac{\varepsilon_{2}}{2}-p_{2}^{e}+\sigma p_{1}^{e}\right)\right] \\
=\pi\left(p_{1}^{e}, p_{2}^{e}\right)+v(\bar{\varepsilon})+\pi\left(p_{2}^{e}, p_{1}^{e}\right)+v(\bar{\varepsilon}),
\end{gathered}
$$


and thus such that

$$
p_{1}^{e}=p_{2}^{e}=p^{M} \equiv \frac{d}{2(1-\sigma)}
$$

The per-producer cartel profit is thus given by $\Pi\left(p^{M}\right)+v(\bar{\varepsilon})-k$.

Lastly, suppose that $R P M$ is introduced, so that the retail price is independent of $\varepsilon_{i}: p_{i}=p_{i}^{e}$. The manufacturer can still capture all the expected profit (not only through the franchise fee, but also through the wholesale price, which now has no influence on the retail price) but, since the price does no adjust to the demand shock, this expected profit is now given by $\pi\left(p_{1}^{e}, p_{2}^{e}\right)-k$ instead of $\pi\left(p_{1}^{e}, p_{2}^{e}\right)+v(\bar{\varepsilon})-k$. In a static context, the manufacturer would thus never impose $R P M$ on the retailer. In a dynamic context, however, $R P M$ might be profitable if it allows the producer to sustain higher prices. To allow for this possibility, we will assume:

Assumption $\Pi\left(p^{N}\right)+v(\bar{\varepsilon})<\Pi\left(p^{M}\right)$.

\section{Tacit Collusion}

\subsection{Franchise contracts}

Each manufacturer $i$ maximizes the expected value of the discounted sum of its profits:

$$
\Pi_{i}=(1-\delta) \sum_{t=0}^{t=\infty} \delta^{t} \Pi_{i}^{t}
$$

where $\Pi_{i}^{t}=\pi\left(p_{i t}, p_{j t}\right)+v(\bar{\varepsilon})-k$. If only franchise contracts can be used, and since it is always optimal for a manufacturer to recover its retailer's profit through the franchise fee, the relevant strategies for manufacturer $i$, denoted $s_{i}$, can be summarized by a sequence of functions $s_{i t}$, setting the expected price for period $t, p_{i t}^{e}$, as a function of the history of observed retail prices in the previous periods. In what follows we concentrate on fully symmetric equilibria (FSE) in which, in any subgame, manufacturers use the same continuation strategy: $s_{1 t}=s_{2 t}$. We denote by $\Pi^{F}$ the maximal payoff that can be obtained in such equilibrium, and by $s^{F}$ the corresponding strategy. Similarly, we denote by $\Pi_{F}$ the minimal payoff that can be obtained and by $s_{F}$ the corresponding strategy.

We show in the Appendix that, given the uniformity of the noise distribution, the best collusive strategy consists in sticking to a collusive expected 
price as long as the realization of the rival's price is consistent with this target, and to "punish" as much as possible any detected deviation; that is, the best collusive strategy is of the form: "agree on an expected price $p^{e}$; if the realized retail prices are compatible with this agreement (that is, $\left.p_{i}, p_{j} \in\left[p^{e}-\bar{\varepsilon} / 2, p^{e}+\bar{\varepsilon} / 2\right]\right)$, then stick to $p^{e}$, otherwise play $s_{F}$." If both manufacturers follow this strategy, their expected profit is equal to $\Pi\left(p^{e}\right)+v(\bar{\varepsilon})-k$.

If a deviation was always detected with probability 1 , no deviation would be profitable if

$$
(1-\delta)\left[\max _{p} \pi\left(p, p^{e}\right)+v(\bar{\varepsilon})-k\right]+\delta \Pi_{F} \leq \Pi\left(p^{e}\right)+v(\bar{\varepsilon})-k,
$$

or

$$
\max _{p} \pi\left(p, p^{e}\right)-\Pi\left(p^{e}\right) \leq \frac{\delta}{1-\delta}\left[\Pi\left(p^{e}\right)+v(\bar{\varepsilon})-k-\Pi_{F}\right]
$$

However, a small deviation $\left(p_{i}^{e} \in\left[p^{e}-\bar{\varepsilon}, p^{e}+\bar{\varepsilon}\right]\right)$ will only be detected with probability $\left|p^{e}-p_{i}^{e}\right| / \bar{\varepsilon}<1$. The expected gain from such a deviation is thus given by

$$
(1-\delta)\left[\pi\left(p_{i}^{e}, p^{e}\right)-\Pi\left(p^{e}\right)\right]-\delta \frac{\left|p^{e}-p_{i}^{e}\right|}{\bar{\varepsilon}}\left[\Pi\left(p^{e}\right)+v(\bar{\varepsilon})-k-\Pi_{F}\right] .
$$

In particular, a "small" deviation ( $p_{i}^{e}$ slightly different from $p^{e}$ ) will not be profitable if (since $\partial \pi\left(p, p^{e}\right) / \partial p=d-(2-\sigma) p^{e}$ for $\left.p=p^{e}\right)$ :

$$
\bar{\varepsilon}\left|d-(2-\sigma) p^{e}\right| \leq \frac{\delta}{1-\delta}\left[\Pi\left(p^{e}\right)+v(\bar{\varepsilon})-k-\Pi_{F}\right]
$$

The two conditions (5) and (6) are actually necessary and sufficient for the sustainability of collusion, which allows the following characterization of the most profitable collusive strategy, conditional on $s_{F}$ and $\Pi_{F}$ :

$s^{F}$ is of the form: "charge an expected price $p^{F}$ as long as all past retail prices belong to $\left[p^{F}-\bar{\varepsilon} / 2, p^{F}+\bar{\varepsilon} / 2\right]$, and play $s_{F}$ otherwise", where $p^{e}=p^{F}$ maximizes $\Pi\left(p^{e}\right)$ subject to (5) and (6).

See Appendix.

In the absence of $R P M$, the most profitable collusive strategy thus consists in maintaining in each period the same expected price, $p^{F}$, which can be shown to be equal to $\min \left\{p^{M}, \bar{p}^{F}\right\}$, where $\bar{p}^{F}$ is the maximal (expected) price satisfying (5) and (6).

Remark: Multiple locations. While we have focussed here on the case where each manufacturer deals with one retailer, the analysis can be extended to the more realistic situation where manufacturers have retailers in 
many different locations, provided that the observation of retail prices by the manufacturers is sufficiently costly - if manufacturers could costlessly observe all retail prices, detecting deviations would become easier. For example, the same analysis as above exactly applies when there are several ex ante identical locations with independent shocks on local demands, assuming that in each period manufacturers observe their rival's retail price in only one randomly selected location. ${ }^{16}$

\subsection{Resale Price Maintenance}

Let us now turn to the case where $R P M$ is allowed. As long as resorting to $R P M$ is observed by the competitor, allowing $R P M$ can only increase the set of equilibria; in particular, the equilibria described above, where manufacturers use franchise contracts and charge $p^{F}$ along the equilibrium path and play $s_{F}$ whenever a deviation if detected for sure, are still equilibria when $R P M$ is allowed but not mandatory: (i) any deviation involving $R P M$ is detected with probability 1 and can thus be punished with the maximal penalty; and (ii) profits from those deviations are lower than those achieved with simple franchise contracts, since $R P M$ makes no use of the retailer's information. The global incentive compatibility condition (5) then ensures that the equilibria resist deviations involving $R P M$.

We now focus on whether $R P M$ generates new equilibria with higher prices and profits. We denote by $\bar{\Pi}$ the maximal payoff that can be obtained in equilibrium when $R P M$ is allowed and by $\bar{s}$ the corresponding strategy; similarly, we denote by $\underline{\Pi}$ the minimal equilibrium payoff and by $\underline{s}$ the corresponding strategy. Allowing $R P M$ can facilitate collusion in two ways: it may be used in punishment paths to allow harsher punishments $\left(\underline{\Pi}<\Pi_{F}\right)$

\footnotetext{
${ }^{16}$ It is optimal to punish "everywhere" a deviation detected in one location. Hence, denoting by $\rho_{i l}=\min \left\{\frac{\left|p^{e}-p_{i l}^{e}\right|}{\bar{\varepsilon}}, 1\right\}$ the probability to detect a deviation to $p_{i l}^{e}$ in location $l$ by observing the retail price in that location, the overall gain from a deviation would be of the form

$$
\begin{array}{r}
\sum_{k}\left[(1-\delta)\left[\pi\left(p_{i l}^{e}, p^{e}\right)-\Pi\left(p^{e}\right)\right]+\delta\left(\frac{1}{n} \times \rho_{i l}\right) \times n\left[\Pi\left(p^{e}\right)+v(\bar{\varepsilon})-k-\Pi_{F}\right]\right] \\
=\sum_{k=1}^{n}\left[(1-\delta)\left[\pi\left(p_{i l}^{e}, p^{e}\right)-\Pi\left(p^{e}\right)\right]+\delta \rho_{i l}\left[\Pi\left(p^{e}\right)+v(\bar{\varepsilon})-k-\Pi_{F}\right]\right],
\end{array}
$$

and no-deviation conditions are thus the same as above.

Note that observing the quantity bought by each retailer may also give the producer additional information about retail prices. However, this information would be limited if, in addition to local shocks, there was also an independent shock on the demand for each product - see the last section of the Appendix for an elaboration of that point.
} 
and on the collusion path to allow an easier detection of deviations (so that we may have $\bar{\Pi}>\Pi^{F}$ even if $\underline{\Pi}=\Pi_{F}$ ). However, when $R P M$ is used on the collusion path, deviations become more attractive as they can rely on franchise contracts to use the retailers' information and generate an additional profit $v(\bar{\varepsilon})$ compared with $R P M$. The following proposition provides a partial characterization of the most profitable collusive equilibrium in which RPM is used in equilibrium (the proof is omitted; it follows the same steps as for Proposition 3.1 but is simpler, due to the fact that any deviation is detected with probability 1$)$ :

The most profitable FSE strategy in which $R P M$ is used along the equilibrium path is of the form: "charge an expected price $p^{R P M}$ as long as all past retail prices are equal to $p^{R P M}$, and play $\underline{s}$ otherwise", where $p^{R P M}$ maximizes $\Pi\left(p^{e}\right)$ subject to

$$
\max _{p} \pi\left(p, p^{e}\right)+v(\bar{\varepsilon})-\Pi\left(p^{e}\right) \leq \frac{\delta}{1-\delta}\left(\Pi\left(p^{e}\right)-k-\underline{\Pi}\right)
$$

The most profitable collusive strategy using RPM in equilibrium thus consists again in maintaining in each period the same expected price, $p^{R P M}$, which can be shown to be equal to $\min \left\{p^{M}, \bar{p}^{R P M}\right\}$, where $\bar{p}^{R P M}$ is the maximal price satisfying (7). This condition has a straightforward interpretation: since deviations are detected with probability one and optimally punished in the toughest way, the optimal deviation consists in maximizing current profits (using a franchise contract, hence the term $\max _{p} \pi\left(p, p^{e}\right)+v(\bar{\varepsilon})$ ). The short-run gain from a deviation is thus larger when $R P M$ is used. It has to be compared to the long-run cost of being detected which in turn is, ceteris paribus, reduced by $v(\bar{\varepsilon})$ when $R P M$ is used (hence the term $\Pi\left(p^{e}\right)-k-\underline{\Pi}$ ). Thus using $R P M$ allows to evade from condition (6) (it facilitates detection) but results in a condition that is more stringent than (5).

We now compare the most profitable equilibria when $R P M$ is available and when it is not. We first focus on the enhanced detection of deviations.

\section{The detection effect}

To focus on the ability to detect deviations, we assume away in this section any impact of $R P M$ on the optimal punishments $\left(\underline{\Pi}=\Pi_{F}\right) \cdot{ }^{17}$ For that

\footnotetext{
${ }^{17}$ This would be the case if the punishment path was restricted to reversal to Nash. [Formally, the analysis of collusion sustained by reversal to Nash is identical to the one presented in this section, setting $k=\Pi\left(p^{N}\right)+v(\bar{\varepsilon})$, and reinterpreting $\Pi(p)-k$ as the difference between profits and static Nash profits.]
} 
purpose, we will suppose in this section that the minmax payoff (which is 0 here) can be sustained in equilibrium, even if $R P M$ is not allowed: $\Pi_{F}=0$. This will be the case if the fixed cost is high enough:

Suppose $\bar{\varepsilon} / d<\sigma /(2-\sigma)^{2}$. For any $\hat{\delta}>0$, there exists $\hat{k}<\Pi\left(p^{N}\right)+v(\bar{\varepsilon})$ such that $\Pi_{F}=0$ for all $k \geq \hat{k}$ and $\delta>\hat{\delta}$.

See appendix.

If the minmax can be achieved in the absence of $R P M$, it can a fortiori be sustained when $R P M$ is allowed: $\underline{\Pi}=\Pi_{F}=0$ and $R P M$ thus does not affect punishments. $R P M$ can therefore help collusion only if used on the equilibrium path. Whether $R P M$ is indeed used in the most profitable equilibrium then depends on the comparison between the profits with $R P M$ at $p^{R P M}$, and the profit that can be obtained using franchise contracts on the collusive path. Since $\Pi=\Pi_{F}$, this boils down to a comparison between $\Pi\left(p^{R P M}\right)$ and $\Pi\left(p^{F}\right)+v(\bar{\varepsilon})$. [From the same arguments as above, the best collusive equilibrium path is stationary and consists of either $p^{F}$ without $R P M$ or $p^{R P M}$ with $R P M$.]

Since $p^{F}$ maximizes $\Pi(p)$ subject to the global and local incentive conditions (5) and (6) (setting $\Pi_{F}$ to 0 ), while $p^{R P M}$ maximizes $\Pi(p)$ subject to (7) (setting $\underline{\Pi}$ to 0 ), which is clearly more stringent than (5), it follows that $R P M$ can benefit collusion only if $p^{F}$ is limited by the local incentive condition (6), since otherwise $p^{R P M} \leq p^{F}$. Furthermore, $p^{R P M}$ must be sufficiently higher than $p^{F}$ to ensure that the increase in expected price outweighs the cost of limiting the retailers' price flexibility. In particular, it must be the case that $\Pi\left(p^{F}\right)+v(\bar{\varepsilon})<\Pi\left(p^{M}\right)$ (otherwise $R P M$ cannot be profitable), which supposes that the discount factor is not too large (since $p^{F}=p^{M}$ for $\delta$ close to 1$)$. Moreover, $p^{R P M}$ must belong to $\left(q^{F}, p^{M}\right]$, where $q^{F}$ denotes the price between $p^{F}$ and $p^{M}$ such that $\Pi\left(q^{F}\right)=\Pi\left(p^{F}\right)+v(\bar{\varepsilon})$, which supposes that the discount factor is not too small (otherwise, both $p^{F}$ and $p^{R P M}$ will be close to $p^{N}$ ). The following Proposition shows that, if the noise is not too important, there exist a range of discount factors where $R P M$ is indeed part of the most profitable collusive strategy:

If $\underline{\Pi}=\Pi_{F}=0$ then, for $\bar{\varepsilon} / d$ small enough there exists $\underline{\delta}$ and $\bar{\delta}>\underline{\delta}$ such that $\bar{s}$ necessarily involves $R P M$ on the equilibrium path for $\underline{\delta}<\delta<\bar{\delta}$. ${ }^{18}$

See appendix.

Propositions 4 and 4 ensure that the above analysis is meaningful. We show in the Appendix that they are jointly compatible: there is an open

\footnotetext{
${ }^{18}$ The only assumption needed for this result is the fact that $\frac{\delta}{1-\delta}(\bar{\Pi}-\underline{\Pi})$ increases with $\delta$, which is trivially the case when $\underline{\Pi}=\Pi_{F}=0$ but is likely to be true in many if not most other cases. [If $\underline{\Pi} \neq \Pi_{F}$, however, the relevant price " $p$ " " is the best price that can be sustained without $R P M$ on the equilibrium path, using $\underline{\Pi}$ (and thus, possibly, $R P M$ ) for punishment.]
} 
range of parameters $(\bar{\varepsilon}, d, k, \delta)$ for which $\Pi_{F}=0$ but the most profitable collusive strategy $\bar{s}$ uses $R P M$ in equilibrium; in that range of parameters, allowing $R P M$ does not enhance the punishments that can be used to deter deviations but leads to an increase of the most profitable collusive price.

\section{$5 \quad$ The effect on punishment}

We now turn to the effect of $R P M$ on punishments. As pointed out above, when adopting $R P M$ is observed by the rival manufacturer, the equilibria derived in the absence of $R P M$ still constitute equilibria when $R P M$ is allowed; therefore, the optimal punishment can only decrease when $R P M$ is allowed $\left(\underline{\Pi} \leq \Pi^{F}\right)$. Furthermore, whenever $\underline{\Pi}<\Pi^{F}$ and $p^{F}<p^{M}$, allowing $R P M$ raises the most profitable equilibrium price - even if $R P M$ is not used on the equilibrium path- since it relaxes both the local and global incentive compatibility. The following proposition establishes that this is indeed the case when there is not too much noise:

For $\bar{\varepsilon} / d$ small enough, there exists $k$ and $\delta$ such that $\Pi_{F}>0=\underline{\Pi}$.

See appendix.

Another case of interest is when a "no-dumping" condition is imposed on the wholesale tariff, that is, when the wholesale price cannot be set below the marginal cost (normalized here to zero):

$$
w \geq 0
$$

Then, since the static Nash equilibrium is precisely obtained for wholesale prices equal to marginal cost, in the absence of $R P M$ no equilibrium price can be lower than $p^{N}$ and thus the static Nash equilibrium constitutes the less profitable equilibrium:

$$
\Pi_{F}=\Pi\left(p^{N}\right)+v(\bar{\varepsilon})-k>0 .
$$

In contrast, $R P M$ opens the possibility to impose retail prices in $\left[0, p^{N}\right]$, at least for some period of time, and it is easy to show that it is possible to sustain a profit (at least slightly) lower than $\Pi\left(p^{N}\right)+v(\bar{\varepsilon})-k ;{ }^{19}$ allowing $R P M$ therefore raises the most profitable collusive price even though it may not be used on the equilibrium path.

\footnotetext{
${ }^{19}$ For example, the equilibrium $\underline{s}$ used to support $\underline{\Pi}=0$ in proposition 5 does not rely on wholesale prices below the marginal cost.
} 


\section{Welfare analysis}

In this section we analyze the welfare implications of allowing $R P M$, assuming that manufacturers coordinate on the best collusive FSE.

If $R P M$ is banned, producers coordinate on the price $p^{F}$. If the only effect of $R P M$ is to reduce the punishment profit $\left(\underline{\Pi}<\Pi_{F}\right.$ but $\bar{s}$ does not use $R P M$ along the equilibrium path), allowing $R P M$ simply increases the expected price and thus is detrimental. When $R P M$ is used in equilibrium, its impact is a priori more ambiguous, since consumers prefer prices that do not react to demand fluctuations.

A measure of welfare is the total surplus $W\left(p_{1}, p_{2} ; \varepsilon_{1}, \varepsilon_{2}\right)$, sum of the consumer surplus, denoted $S\left(p_{1}, p_{2} ; \varepsilon_{1}, \varepsilon_{2}\right)$, and total profit. Using $\partial S / \partial p_{i}=$ $-D_{i}$ and $\pi_{i}=p_{i} D_{i}$, we have:

$$
\begin{aligned}
\frac{\partial W}{\partial p_{i}}\left(p_{1}, p_{2} ; \varepsilon_{1}, \varepsilon_{2}\right) & =\left(\frac{\partial S}{\partial p_{i}}+\frac{\partial \pi_{i}}{\partial p_{i}}+\frac{\partial \pi_{j}}{\partial p_{i}}\right)\left(p_{1}, p_{2} ; \varepsilon_{1}, \varepsilon_{2}\right) \\
& =-\left(d+\varepsilon_{i}-p_{i}+\sigma p_{j}\right)+\left(d+\varepsilon_{i}-2 p_{i}+\sigma p_{j}\right)+\left(\sigma p_{j}\right) \\
& =-p_{i}+\sigma p_{j} .
\end{aligned}
$$

Integrating, the total surplus is given by:

$$
W\left(p_{1}, p_{2} ; \varepsilon_{1}, \varepsilon_{2}\right)=C\left(\varepsilon_{1}, \varepsilon_{2}\right)-\frac{1}{2}\left(p_{1}^{2}+p_{2}^{2}-2 \sigma p_{1} p_{2}\right)
$$

If the two prices have the same expected value $p^{e}$, the expected total surplus is thus:

$$
W^{e}=C^{e}-(1-\sigma)\left(p^{e}\right)^{2}-\frac{1}{2}\left(\operatorname{Var}\left[p_{1}\right]+\operatorname{Var}\left[p_{2}\right]\right) .
$$

Therefore, for a given expected price $p^{e}, R P M$ increases total surplus. However, there is a real conflict between firms' interest and consumer or total welfare: consumers like stable prices whereas firms prefer to let them react to demand conditions. Therefore, while $R P M$ has potentially a positive effect on consumer surplus due to the stabilization of prices, manufacturers will adopt $R P M$ only if it leads to an increase of prices large enough to compensate them. The following proposition shows that this is precisely the case where it harms welfare -and a fortiori consumer surplus- when the scope for collusion is substantial; in that case, banning $R P M$ is socially optimal:

When either $p^{F} \geq p^{M} / 2$ or $p^{R P M}>p^{M}-p^{N}$, allowing $R P M$ can only reduce welfare. 
Suppose first that $\Pi_{F}=\underline{\Pi}$. Then $R P M$ is used in equilibrium if

$$
\Pi\left(p^{R P M}\right)-\Pi\left(p^{F}\right)=(1-\sigma)\left(p^{R P M}-p^{F}\right)\left[2 p^{M}-\left(p^{R P M}+p^{F}\right)\right]>v(\bar{\varepsilon}) .
$$

Since $\operatorname{Var}\left[p_{i}\right]=v(\bar{\varepsilon})$ under franchise contracts, total welfare decreases when $R P M$ is allowed if

$$
(1-\sigma)\left(p^{R P M}\right)^{2}>(1-\sigma)\left(p^{F}\right)^{2}+v(\bar{\varepsilon}),
$$

or:

$$
(1-\sigma)\left(p^{R P M}-p^{F}\right)\left(p^{R P M}+p^{F}\right)>v(\bar{\varepsilon}) .
$$

It is immediate that (8) implies (9) if

$$
p^{R P M}+p^{F} \geq p^{M}
$$

This is clearly true if $p^{R P M}>p^{M}-p^{N}$, because $p^{F}>p^{N}$. This is also true when $p^{F}>p^{M} / 2$, since (8) implies $p^{R P M}>p^{F}$.

If $\Pi_{F}>\underline{\Pi}$, the effect is reinforced. The best price with franchise is $\hat{p}^{F}>$ $p^{F}$ so that welfare is reduced if along the equilibrium path $\bar{s}$ involves franchise contracts with $\hat{p}^{F}$ or $R P M$ contracts with $p^{R P M}$ and $\hat{p}^{F}+p^{R P M}>p^{M}$.

Note that $\sigma<2 / 3$ implies $p^{N}>p^{M} / 2$ and thus $p^{F} \geq p^{M} / 2$; hence:

If $\sigma<2 / 3$, allowing $R P M$ can only reduce total welfare.

\section{Retail cost uncertainty}

While we have focused on shocks on the demand side, a similar analysis can be conducted when the shocks affect retail costs. The general point is that retailers' prices tend to respond to variations in both the demand they face and their (marginal) costs. RPM prevents adjustments to such local variations and thus facilitates the detection of deviations in producers' tariffs.

To see that, assume that demand is not stochastic, $D_{i}\left(p_{i}, p_{j}\right)=d-p_{i}+\sigma p_{j}$, but retail cost is. We normalize the average retail costs to zero so that the retail cost of retailer $i$ is $\varepsilon_{i}$, uniformly distributed on the interval $[-\bar{\varepsilon}, \bar{\varepsilon}]$. The timing of information is the same as before, in particular contracts are signed before the retailer observes its cost.

Given a wholesale price $w_{i}$ the retailer sets a price

$$
p_{i}=\arg \max _{p}\left(p-w_{i}-\varepsilon_{i}\right)\left(d-p+\sigma p_{j}^{e}\right)-A_{i} .
$$


It follows that in the absence of $R P M$ the retail price is still of the form

$$
p_{i}=p_{i}^{e}+\frac{\varepsilon_{i}}{2},
$$

where

$$
p_{i}^{e}=\frac{d+w_{i}+\sigma p_{j}^{e}}{2}
$$

as before. The expected profit is then $\pi\left(p_{i}^{e}, p_{j}^{e}\right)+v(\bar{\varepsilon})$, as with demand uncertainty.

The analysis of the equilibrium strategies conducted for the case of demand uncertainty carries over to the case of cost uncertainty; since the set of equilibria depends only on the "reduced" profit function and the relationship between the producers' strategy and the observed retail prices, $p_{i}=p_{i}^{e}+\varepsilon_{i} / 2$. Therefore, all the results up to Proposition 7 remain valid for the case where $\varepsilon_{i}$ is interpreted as a shock on retailer $i$ 's marginal cost.

The main difference concerns welfare effects, as it is socially beneficial to let retail prices react to the shocks on the costs. Using $\pi_{i}=\left(p_{i}-\varepsilon_{i}\right) D_{i}$, the same derivation as before shows that, for a common expected price $p^{e}$, the expected total surplus is given by:

$$
W^{e}=C-(1-\sigma)\left(p^{e}\right)^{2}-\frac{1}{2}\left(\operatorname{Var}\left[p_{1}-\varepsilon_{1}\right]+\operatorname{Var}\left[p_{2}-\varepsilon_{2}\right]\right),
$$

where $C$ is a constant. Hence, $R P M$ should clearly be banned since it has only negative effects on welfare; it increases the best collusive expected price and moreover prevents prices from adjusting to retail costs:

With no demand uncertainty and retail cost uncertainty, allowing $R P M$ can only reduce welfare.

\section{Unobserved contracts}

We have assumed so far that the type of contract (franchise or $R P M$ ) was observable to all parties. We now discuss the case of secret contracts. We assume here that $\Pi_{F}=\underline{\Pi}=0$, which holds true if $k$ is close to $\Pi\left(p^{N}\right)+v(\bar{\varepsilon})$.

The fact that contracts are secret does not affect the maximal price $p^{R P M}$ that can be sustained when $R P M$ is used in equilibrium but may affect the most profitable strategy based on franchise contracts, since secretly switching to $R P M$ creates a new possibility of deviation. For example, starting from a franchise contract with $p^{F}$, a firm can impose $R P M$ and a retail price $p$ between $p^{F}-\bar{\varepsilon} / 2$ and $p^{F}$ : it will lose $v(\bar{\varepsilon})$ but will not be detected by the rival since the price remains in the admissible range. 
The price $p^{F}$ and strategy $s^{F}$ previously characterized still form an equilibrium if

$$
\max _{0 \leq x \leq \frac{\bar{\varepsilon}}{2}}\left\{\pi\left(p^{F}-x, p^{F}\right)-\Pi\left(p^{F}\right)-v(\bar{\varepsilon})\right\} \leq 0
$$

or

$$
\left.\max _{0 \leq x \leq \frac{\bar{\varepsilon}}{2}}\left\{\left((2-\sigma) p^{F}-d\right)\right) x-x^{2}\right\} \leq v(\bar{\varepsilon})
$$

Straightforward computations show that this is possible only if

$$
p^{F} \leq p^{N}+\frac{\bar{\varepsilon}}{(2-\sigma) \sqrt{3}} .
$$

This is the case if $\bar{\varepsilon}$ is large or $\delta$ is small, since in both instances $p^{F}$ is small. The non observability of contracts then does not affect the equilibrium.

If condition (11) is not satisfied, the price $p^{F}$ can no longer be sustained when contracts are secret and $R P M$ is allowed. In this case, allowing $R P M$ has two opposite effects. It reduces the most profitable collusive price based on franchise contracts to a lower price $\hat{p}^{F}<p^{F}$, which increases welfare, but manufacturers may then prefer to resort to $R P M$ and implement $p^{R P M}$, which, for levels of prices that are not too small, reduces welfare. ${ }^{20}$

\section{Comparison with other vertical arrangements}

Other vertical restraints than $R P M$ may affect the variability of retail prices and, therefore, the scope for collusion; it is thus interesting to compare $R P M$ with those other arrangements in the light of the above analysis.

\subsection{Intrabrand competition}

As a benchmark, consider first the case where manufacturers promote strong intrabrand competition among their retailers. Assuming pure Bertrand competition, retail prices would then respond $100 \%$ to changes in retail costs and not at all to changes in demand. Therefore, promoting intrabrand competition does not facilitate the detection of producers' deviations from a collusive path when there are shocks on retail costs. Furthermore, even in the case of demand shocks, promoting intrabrand competition does not facilitate the

\footnotetext{
${ }^{20}$ However, it can be shown that even with secret contracts there exists an open range of parameters under which allowing $R P M$ reduces welfare.
} 
detection of deviations as effectively as $R P M$ whenever retailers are not perfect competitors (e.g., because of differentiation) or marginal costs are not constant (with decreasing returns to scale, variations in the size of demand would affect retail prices).

\subsection{Exclusive territories}

Granting exclusive territories reduces intrabrand competition and tends to give retailers more freedom in the setting of their prices. Therefore, exclusive territories tend to increase the variability of retail prices in the presence of local shocks on consumer demand. For example, in the linear model, retail prices half respond to changes in the size of demand if retailers are granted exclusive territories, whereas they do not respond at all to such changes if, in each location, there is head-to-head competition between rival retailers. Therefore, exclusive territories tend to make producers' deviations more difficult to detect when there are local shocks on consumer demand.

Retail prices always respond to local shocks on retail costs, however, whether retailers benefit from exclusive territories or not. For example, in the linear model, retail prices half respond to variations in retail (marginal) costs if retailers are granted exclusive territories, whereas they fully respond to such changes if there is perfect intrabrand competition. Therefore, exclusive territories tend to reduce the variability of retail prices, but not to the same extent as RPM, which therefore still facilitates the detection of producers' deviations from a collusive path.

\subsection{Quotas}

Quantity quotas, even in the form of quantity floors or ceilings, contribute to increase the variability of retail prices when there are local shocks on consumer demand. For example, assume that producer $i$ imposes a minimal quota $\underline{q}$ and a maximal quota $\bar{q} \geq \underline{q}$ in the above linear model (a fixed quota would correspond to the case $\bar{q}=\underline{q}$ ). Given the rival's expected retail price $p_{j}^{e}$, retailer $i$ will then set a price $p_{i}$ given by

$$
\begin{array}{rlr}
p_{i} & =d+\varepsilon_{i}+\sigma p_{j}^{e}-\bar{q} & \text { if } d+\varepsilon_{i}+\sigma p_{j}^{e}+w_{i}>2 \bar{q}, \\
& =\frac{d+\varepsilon_{i}+\sigma p_{j}^{e}+w_{i}}{2} & \text { if } 2 \bar{q}>d+\varepsilon_{i}+\sigma p_{j}^{e}+w_{i}>2 \underline{q}, \\
& =d+\varepsilon_{i}+\sigma p_{j}^{e}-\underline{q} & \text { if } d+\varepsilon_{i}+\sigma p_{j}^{e}+w_{i}<2 \underline{q} .
\end{array}
$$

That is, the retail price only half responds to changes in the demand size $d_{i}\left(d p_{i} / d \varepsilon_{i}=1 / 2\right)$ when quotas are not binding, but respond fully to 
such changes $\left(d p_{i} / d \varepsilon_{i}=1\right)$ when quotas are binding, which exacerbates their variability (for instance, the introduction of a fixed quota doubles the range of retail prices). ${ }^{21}$

\subsection{Nonlinear tariffs}

Nonlinear wholesale tariffs might also reduce the variability of retail prices. Of course, nonlinear tariffs may involve transaction costs that reduce their appeal. But retailers' arbitrage, too, limits their effectiveness in reducing retail price variability. To see this in the simplest way, we briefly show here that retailers' arbitrage limits a monopolistic producer's ability to reduce the variability of a retailer's price through nonlinear wholesale tariffs; we show formally in the last section of the Appendix that the insights carry over to the duopoly context analyzed above.

Consider a monopolist producer dealing with $n$ retailers, each of them a local monopolist bearing no retail cost and facing a linear demand $D_{i}\left(\varepsilon_{i}, p_{i}\right)=$ $d+\varepsilon_{i}-p_{i}$, where local shocks $\varepsilon_{i}$ are independently and identically distributed. The intuition is that if retailers coordinate their supply decisions, the producer cannot hope to control each retailer's individual price but only an "average" price; as a result, the producer cannot prevent individual prices from at least partially responding to demand fluctuations. Furthermore, as the number of retailers increases, the producer will loose more and more control over the distribution of retail prices and, in the limit (for a very large number of retailers), it cannot do better than with simple two-part tariffs.

Assuming that retailers can perfectly coordinate their buying decisions, if the producer offers nonlinear tariffs $\left(t_{k}\left(q_{k}\right)\right)_{k=1, \ldots, n}$ and retailers want to buy a total quantity $Q$, they will buy $\left(\bar{q}_{k}\right)_{k=1, \ldots, n}$ solution to

$$
\min _{\left(q_{k}\right)_{k=1, \ldots, n}} \quad \sum_{k} t_{k}\left(q_{k}\right)
$$

and then redistribute quantities and share the total payment to the producer, $\bar{t}(Q) \equiv \sum_{k} t_{k}\left(\bar{q}_{k}\right)$, so as to ensure that each of them gains from participating in this arbitrage. ${ }^{22}$ Therefore, for a given realization of the shocks $\left(\varepsilon_{k}\right)_{k=1, . ., n}$, the retailers will choose to sell quantities $\hat{q}_{k}$ solution to

$$
\max _{\left(q_{k}\right)_{k=1, \ldots, n}} \sum_{k}\left(d+\varepsilon_{k}-q_{k}\right) q_{k}-\bar{t}\left(\sum_{k} q_{k}\right)
$$

\footnotetext{
${ }^{21}$ In the case of shocks on retail costs, however, a minimal quota is formally equivalent to a price ceiling whereas a maximal quota is equivalent to a price floor.

${ }^{22}$ The precise transfers are not relevant for the present analysis, so long as retailers can reach an agreement and agree on the payment-minimizing allocation $\bar{q}_{i k}$.
} 
and characterized (assuming an interior solution) by ${ }^{23}$

$$
\hat{q}_{k}=\frac{d+\varepsilon_{k}-\bar{t}^{\prime}\left(\sum_{k} \hat{q}_{k}\right)}{2}, k=1, \ldots, n .
$$

Adding-up those conditions shows that the total quantity $\hat{Q} \equiv \sum_{k} \hat{q}_{k}$ is solution to

$$
\hat{Q}=\frac{n d+\sum_{k} \varepsilon_{k}-n \bar{t}^{\prime}(\hat{Q})}{2},
$$

so that the total quantity $\hat{Q}$ is a function of the local shocks only through their sum $\sum_{k} \varepsilon_{k}$. Building on this observation, conditions (12) yield

$$
\hat{p}_{k}=d+\varepsilon_{k}-\hat{q}_{k}=\frac{d+\varepsilon_{k}+\bar{t}^{\prime}\left(\hat{Q}\left({ }_{k} \varepsilon_{k}\right)\right)}{2} .
$$

Therefore, even if the producer could design at will the function $f(\varepsilon) \equiv$ $\bar{t}^{\prime}(\hat{Q}(\varepsilon))$, the variance of retail price $p_{1}$, say, would be of the form

$$
\operatorname{Var}\left(\frac{\varepsilon_{1}}{2}+\frac{f\left({ }_{k} \varepsilon_{k}\right)}{2}\right)=\frac{1}{4} \operatorname{Var}\left(\varepsilon_{1}+f\left({ }_{k} \varepsilon_{k}\right)\right) .
$$

This variance is minimized for $f\left(\sum_{k} \varepsilon_{k}\right)=-E\left[\varepsilon_{1} \mid \sum_{k} \varepsilon_{k}\right]$ (proof in Appendix) and is then equal to

$$
\frac{1}{4}\left\{\operatorname{Var}\left[\varepsilon_{1}\right]-\operatorname{Var}\left[E\left[\left.\varepsilon_{1}\right|_{k} \varepsilon_{k}\right]\right]\right\}
$$

This minimal variance increases with the number of retailers $n$ : the aggregate shock $\sum_{k} \varepsilon_{k}$ provides less and less information on any particular individual shock $\varepsilon_{i}$ when the number of location increases, so that the second term in the above expression decreases when $n$ increases. In the limit ( $n$ very large) the aggregate shock provides no information at all on any individual shock; the second term thus disappears $\left(E\left[\varepsilon_{1} \mid \sum_{k} \varepsilon_{k}\right]=E\left[\varepsilon_{1}\right]\right.$ and its variance is zero) and the minimal variance is thus equal to $\operatorname{Var}\left[\varepsilon_{1}\right] / 4$, which is the variance of retail prices generated by two-part tariffs.

Therefore, as the number of retailers increases, the producer is less and less able to reduce the variability of a retailer's price through nonlinear tariffs. When the number of retailers is large, nonlinear tariffs cannot help reduce

\footnotetext{
${ }^{23}$ We use a differentiable approach for conciseness, but the argument is valid for any mechanism.
} 
a retail price variability, as compared with simple two-part tariffs. Furthermore, even if the number of retailers is limited, nonlinear tariffs improve over two-part tariffs but can never be as efficient as $R P M$ in reducing retail price volatility whenever there are at least two retailers (for $n=2$, the above minimal variance is $\left.\operatorname{Var}\left[\varepsilon_{1}\right] / 8>0\right)$. 


\section{References}

Abreu, D. (1986), "Extremal Equilibria of Oligopolistic Supergames", Journal of Economic Theory, 39:191-225.

Abreu, D., D. Pearce and E. Stachetti (1986), "Optimal Cartel Equilibria with Imperfect Monitoring", Journal of Economic Theory, 39:251-269.

Abreu, D., D. Pearce and E. Stachetti (1990), "Toward a Theory of Discounted Repeated Games with Imperfect Monitoring", Econometrica, 58:1041-1063.

Aghion, P. and P. Bolton (1987), "Contracts as a Barrier to Entry", American Economic Review, 77:388-401.

Athey S. and K. Bagwell (1998): "Optimal Collusion under Private Information", mimeo MIT

Athey S., K. Bagwell and C Sancharico (1998): "Collusion and Price Rigidity", mimeo MIT.

Besanko, D. and M. K. Perry (1997), "Resale Price Maintenance and Service with Perfectly Competitive Retailers", mimeo.

Caillaud, B. and P. Rey, (1987): "A Note on Vertical Restraints with Provision of Distribution Services", INSEE Discussion Paper No. 8702.

Comanor, W. S. and P. Rey (1998), "Vertical Restraints and the Market Power of Large Distributors", forthcoming Review of Industrial Organization.

Green, E. and R. Porter (1984): "Non-cooperative Collusion Under Imperfect Price Information", Econometrica, 52:87-100.

Hart, O. and J. Tirole (1990), "Vertical Integration and Market Foreclosure," Brookings Papers on Economic Activity: Microeconomics, 205-285.

O'Brien, D. and G. Shaffer (1992), "Vertical Control with Bilateral Contracts", Rand Journal of Economics, 23:299-308.

OECD (1994), Competition policy and Vertical Restraints: Franchising Agreements, Paris.

Rey, P. and J. E. Stiglitz (1988), "Vertical Restraints and Producers' Competition", European Economic Review, 32:561-568.

Rey, P. and J. E. Stiglitz (1995), "The Role of Exclusive Territories in Producers' Competition", Rand Journal of Economics, 26:431-451.

Rey, P. and J. Tirole (1986), "Vertical Restraints from a Principal-Agent Viewpoint", in L. Pellegrini and S. Reddy eds., Marketing Channels: Relationships and Performance, Lexington Books, Lexington, Massachusetts, 3-30.

Rey, P. and J. Tirole (1996), "A Primer on Foreclosure", mimeo.

Rey, P. and T. Vergé (1999), "Resale Price Maintenance and Horizontal Cartel", mimeo.

Slade, M. (1998), "Beer and the Tie: Did Divestiture of Brewer-Owned Public Houses Lead to Higher Beer Prices", Economic Journal, 108:565-602. 
Spence, A. M. (1975), "Monopoly, Quality and Regulation", Bell Journal of Economics, 6:417-429. 


\section{A Proof of Proposition 3.1}

If the expected price is equal to $p^{e}$ at some point on an equilibrium path, then the following strategy is an equilibrium strategy:

"charge the expected price $p^{e}$, and then play $s^{F}$ if the realized prices belong to $\left[p^{e}-\frac{\bar{\varepsilon}}{2}, p^{e}+\frac{\bar{\varepsilon}}{2}\right]^{2}$, and $s_{F}$ otherwise."

Consider an equilibrium and an history along the equilibrium path leading to the expected price $p^{e}$, and let $V\left(p_{1}, p_{2}\right)$ be the continuation value of the game at this date, as a function of the realized prices. Then

$$
p^{e} \in \arg \max _{p}\left\{(1-\delta)\left[\pi\left(p, p^{e}\right)+v(\bar{\varepsilon})-k\right]+\delta E\left[V\left(p+\frac{\varepsilon_{1}}{2}, p^{e}+\frac{\varepsilon_{2}}{2}\right)\right]\right\},
$$

where $\Pi_{F} \leq V \leq \Pi^{F}$.

We now show that manufacturers have no incentive to deviate from the candidate equilibrium described above. Manufacturers' candidate equilibrium payoff is

$$
(1-\delta)\left[\Pi\left(p^{e}\right)+v(\bar{\varepsilon})-k\right]+\delta \Pi^{F} \geq(1-\delta)\left[\Pi\left(p^{e}\right)+v(\bar{\varepsilon})-k\right]+\delta E\left[V\left(p+\frac{\varepsilon_{1}}{2}, p+\frac{\varepsilon_{2}}{2}\right)\right] .
$$

The payoff of deviating and charging $p \notin\left[p^{e}-\bar{\varepsilon}, p^{e}+\bar{\varepsilon}\right]$ is instead given by

$$
(1-\delta)\left[\pi\left(p, p^{e}\right)+v(\bar{\varepsilon})-k\right]+\delta \Pi_{F} \leq(1-\delta)\left[\pi\left(p, p^{e}\right)+v(\bar{\varepsilon})-k\right]+\delta E\left[V\left(p+\frac{\varepsilon_{1}}{2}, p^{e}+\frac{\varepsilon_{2}}{2}\right)\right]
$$

and is thus smaller than in the original equilibrium; therefore, this deviation is not profitable. The payoff of a deviation to $p \in] p^{e}-\bar{\varepsilon}, p^{e}[$ is given by

$$
(1-\delta)\left[\pi\left(p, p^{e}\right)+v(\bar{\varepsilon})-k\right]+\delta \Pi^{F}+\delta \frac{\left(p^{e}-p\right)}{\bar{\varepsilon}}\left(\Pi_{F}-\Pi^{F}\right)
$$

But, since the distribution of the demand shock is uniform and $\Pi_{F} \leq$ 
$V \leq \Pi^{F}:$

$$
\begin{aligned}
& E\left[V\left(p+\frac{\varepsilon_{1}}{2}, p^{e}+\frac{\varepsilon_{2}}{2}\right)\right]-E\left[V\left(p^{e}+\frac{\varepsilon_{1}}{2}, p^{e}+\frac{\varepsilon_{2}}{2}\right)\right] \\
= & \int_{-\bar{\varepsilon}}^{\bar{\varepsilon}} \int_{-\bar{\varepsilon}}^{\bar{\varepsilon}}\left[V\left(p+\frac{\varepsilon_{1}}{2}, p^{e}+\frac{\varepsilon_{2}}{2}\right)-V\left(p^{e}+\frac{\varepsilon_{1}}{2}, p^{e}+\frac{\varepsilon_{2}}{2}\right)\right] \frac{d \varepsilon_{1} d \varepsilon_{2}}{4 \bar{\varepsilon}^{2}} \\
= & \int_{-\bar{\varepsilon}}^{\bar{\varepsilon}}\left[\int_{p-\frac{\bar{\varepsilon}}{2}}^{p+\frac{\bar{\varepsilon}}{2}} V\left(x, p^{e}+\frac{\varepsilon_{2}}{2}\right) \frac{d x}{\bar{\varepsilon}}-\int_{p^{e}-\frac{\bar{\varepsilon}}{2}}^{p^{e}+\frac{\bar{\varepsilon}}{2}} V\left(x, p^{e}+\frac{\varepsilon_{2}}{2}\right) \frac{d x}{\bar{\varepsilon}}\right] \frac{d \varepsilon_{2}}{2 \bar{\varepsilon}} \\
= & \int_{-\bar{\varepsilon}}^{\bar{\varepsilon}}\left[\int_{p-\frac{\bar{\varepsilon}}{2}}^{p^{e}-\frac{\bar{\varepsilon}}{2}} V\left(x, p^{e}+\frac{\varepsilon_{2}}{2}\right) \frac{d x}{\bar{\varepsilon}}-\int_{p+\frac{\bar{\varepsilon}}{2}}^{p^{e}+\frac{\bar{\varepsilon}}{2}} V\left(x, p^{e}+\frac{\varepsilon_{2}}{2}\right) \frac{d x}{\bar{\varepsilon}}\right] \frac{d \varepsilon_{2}}{2 \bar{\varepsilon}} \\
\geq & \int_{-\bar{\varepsilon}}^{\bar{\varepsilon}}\left[\int_{p-\frac{\bar{\varepsilon}}{2}}^{p^{e}-\frac{\bar{\varepsilon}}{2}} \Pi_{F} \frac{d x}{\bar{\varepsilon}}-\int_{p+\frac{\bar{\varepsilon}}{2}}^{p^{e}+\frac{\bar{\varepsilon}}{2}} \Pi^{F} \frac{d x}{\bar{\varepsilon}}\right] \frac{d \varepsilon_{2}}{2 \bar{\varepsilon}} \\
= & \frac{p^{e}-p}{\bar{\varepsilon}}\left(\Pi_{F}-\Pi^{F}\right) .
\end{aligned}
$$

Therefore, the payoff generated by a deviation to $p \in] p^{e}-\bar{\varepsilon}, p^{e}[$ is again smaller in the new candidate equilibrium then in the original equilibrium, and the deviation is thus not profitable. A similar reasoning holds for $p>p^{e}$.

The set of expected prices $p^{e}$ that can be sustained at some point on an equilibrium path is a closed interval $I^{F}$, which is the set of prices satisfying both

$$
\max _{p} \pi\left(p, p^{e}\right)-\Pi\left(p^{e}\right) \leq \frac{\delta}{1-\delta}\left(\Pi^{F}-\Pi_{F}\right)
$$

and

$$
\bar{\varepsilon}\left|d-(2-\sigma) p^{e}\right| \leq \frac{\delta}{1-\delta}\left(\Pi^{F}-\Pi_{F}\right)
$$

If the expected price $p^{e}$ is sustained at some point in an equilibrium, then the strategy described in the previous lemma must form a FSE, and thus

$$
\max _{p}\left\{(1-\delta)\left[\pi\left(p, p^{e}\right)-\Pi\left(p^{e}\right)\right]-\delta \inf \left\{\frac{\left|p^{e}-p\right|}{\bar{\varepsilon}}, 1\right\}\left(\Pi^{F}-\Pi_{F}\right)\right\} \leq 0 .
$$

Conversely, if this condition is satisfied for a given $p^{e}$, then the strategy described in the previous lemma indeed form a FSE, in which in the first period the expected price is $p^{e}$. Therefore an expected price $p^{e}$ can be sustained at some point in a FSE if and only if it satisfies (16).

This condition clearly implies both (14) and (15): (15) is the local version of (16) (for prices $p$ slightly different from $p^{e}$ ) while (14) involves a (weakly) 
larger probability of detection than (16) and a deviation that is profitable when detected with probability 1 would a fortiori remain profitable for a smaller probability of detection. We now show that, together, (14) and (15) imply (16). Suppose this was not the case. This implies that the optimal deviation involves a price $p$ insufficiently different from $p^{e}$ for being detected with probability $1\left(p \in\left[p^{e}-\bar{\varepsilon}, p^{e}+\bar{\varepsilon}\right]\right)$, otherwise (14) would be violated. If for example this price $p$ is below $p^{e}$, then

$$
\pi\left(p, p^{e}\right)-\Pi\left(p^{e}\right)-\frac{\delta}{1-\delta} \frac{p^{e}-p}{\bar{\varepsilon}}\left(\Pi^{F}-\Pi_{F}\right)>0 .
$$

But the function that appears in the left-hand side is concave in $p$ and equal to 0 for $p=p^{e}$; therefore, its slope is necessarily negative for $p=p^{e}$, which violates (15). The argument is similar if the optimal deviation price $p$ is above $p^{e}$.

Lastly, since both the left-hand sides of (14) and (15) are convex in $p^{e}$, the set of prices satisfying both constraints is an interval.

Defining

$$
\hat{p}^{F}=\arg \max _{p \in I^{F}} \Pi(p)
$$

we can now prove Proposition 3.1. First, by definition of $\hat{p}^{F}$, we have $\Pi^{F} \leq$ $\Pi\left(\hat{p}^{F}\right)+v(\bar{\varepsilon})-k$. Moreover, since the strategy described in the above lemma generates a FSE, we have

$$
\Pi^{F} \geq(1-\delta)\left[\Pi\left(\hat{p}^{F}\right)+v(\bar{\varepsilon})-k\right]+\delta \Pi^{F} .
$$

Therefore $\Pi^{F}=\Pi\left(\hat{p}^{F}\right)+v(\bar{\varepsilon})-k$, which is possible only if $\hat{p}^{F}$ is played with probability one at all dates. Furthermore, $p^{e}=\hat{p}^{F}$ satisfies (14) and (15) with $\Pi^{F}=\Pi\left(\hat{p}^{F}\right)+v(\bar{\varepsilon})-k$, and thus also satisfies (5) and (6). The conclusion $\left(\hat{p}^{F}=p^{F}\right)$ follows from the fact that, conversely, any price satisfying (5) and (6) belongs to $I^{F}$. To see that, it suffices to note that (5) and (6) imply (the argument is similar to that given above for the equivalence of (16) with (14) and (15))

$\max _{p}\left\{(1-\delta)\left[\pi\left(p, p^{e}\right)-\Pi\left(p^{e}\right)\right]-\delta \inf \left\{\frac{\left|p^{e}-p\right|}{\bar{\varepsilon}}, 1\right\}\left(\Pi\left(p^{e}\right)+v(\bar{\varepsilon})-k-\Pi_{F}\right)\right\} \leq 0$,

which in turn implies that adopting the strategy "charge the expected price $p^{e}$ as long as the realized prices belong to $\left[p^{e}-\bar{\varepsilon} / 2, p^{e}+\bar{\varepsilon} / 2\right]^{2}$, and play $s_{F}$ otherwise" constitutes an equilibrium. 


\section{B Proof of proposition 4}

Let $\Pi_{0}^{F}(\delta)$ be the maximal profit that can be sustained assuming that $\Pi_{F}=$ 0 , and denote by $s_{0}^{F}(\delta)$ and $p_{0}^{F}(\delta)$ the corresponding strategy and collusive expected price. For any given $\delta, p_{0}^{F}(\delta)$ is at least as high as the price that can be supported by a reversal to Nash, which itself is strictly above $p^{N}$ for $\delta>0$.

Choose $p$ such that

$$
\max \{\Delta(\underline{p}), \bar{\varepsilon}[d-(2-\sigma) \underline{p}]+\Pi(\underline{p})\}+v(\bar{\varepsilon})-k=0,
$$

where

$$
\Delta(p) \equiv \max _{q} \pi(q, p)=\frac{(d+\sigma p)^{2}}{4} .
$$

The assumption $\bar{\varepsilon} / d<\sigma /(2-\sigma)^{2}$ ensures that $\bar{\varepsilon}[d-(2-\sigma) p]+\Pi(p)$ increases in $p$ for $p \leq p^{N}$; since $\Delta(p)$ also increases in $p$ and $\Delta\left(p^{N}\right)=\Pi\left(p^{N}\right)$ :

- The price $p$ increases with $k$ and goes up to $p^{N}$ as $k$ increases up to $\Pi\left(p^{N}\right)+\bar{v}(\bar{\varepsilon})$.

- For any $\hat{\delta}$ there exists $\hat{k}$ such that, for any $\delta \geq \hat{\delta}$ and $k \in\left[\hat{k}, \Pi\left(p^{N}\right)+v(\bar{\varepsilon})\right]$ the price $\underline{p}$ characterized by (18) is well-defined and satisfies: ${ }^{24}$

$$
\delta \Pi_{0}^{F}(\delta)+(1-\delta)(\Pi(\underline{p})+v(\bar{\varepsilon})-k)>0 .
$$

To show that $\Pi_{F}=0$, we use the following punishment path:

$$
\begin{aligned}
p_{t}^{P} & =\underline{p} \text { for } t=0, \ldots, T-1, \\
p_{t}^{P} & =\hat{p} \text { for } t=T, \\
p_{t}^{P} & =p_{0}^{F}(\delta) \text { for } t>T,
\end{aligned}
$$

where $T \geq 1$ and $\hat{p} \in\left[\underline{p}, p_{0}^{F}(\delta)\right]$ are chosen so that

$$
(1-\delta) \sum_{t=0}^{T} \delta^{t}[\Pi(\underline{p})+v(\bar{\varepsilon})-k]+(1-\delta) \delta^{T}[\Pi(\hat{p})+v(\bar{\varepsilon})-k]+\delta^{T+1} \Pi_{0}^{F}(\delta)=0 .
$$

\footnotetext{
${ }^{24}$ Note that $p_{0}^{F}(\delta)$ is a non decreasing function of $\delta$. Therefore, if (19) is satisfied for $\delta=\hat{\delta}$, it is satisfied for any $\delta>\hat{\delta}$. And for any $\hat{\delta},(19)$ is satisfied for $k=\Pi\left(p^{N}\right)+v(\bar{\varepsilon})$ (since then $\underline{p}=p^{N}$ and $p_{0}^{F}(\delta)>p^{N}$ ), so that there exists $\hat{k}$ such that (19) remains satisfied (for $\delta=\hat{\delta}$ ) for any $k \geq \hat{k}$.
} 
Such $T$ and $\hat{p}$ always exist from (19). Assuming that deviations from this punishment path (realized prices $\left(p_{t 1}, p_{t 2}\right)$ outside the appropriate range $\left.\left[p_{t}^{P}-\bar{\varepsilon} / 2, p_{t}^{P}+\bar{\varepsilon} / 2\right]^{2}\right)$ are themselves punished by returning to the beginning of the punishment path, we now show that no such deviations are profitable. As usual, it suffices to consider one-period deviations and, moreover, since by construction deviations are ruled out in periods $t>T$, we restrict attention to the first $T+1$ periods.

By sticking to the above strategy, in each period $\tau<T$, a manufacturer's expected profit is given by

$$
\begin{aligned}
\Pi_{\tau}= & (1-\delta) \sum_{t=\tau}^{T-1} \delta^{t-\tau}[\Pi(\underline{p})+v(\bar{\varepsilon})-k] \\
& +(1-\delta) \delta^{T-\tau}[\Pi(\hat{p})+v(\bar{\varepsilon})-k]+\delta^{T-\tau+1} \Pi_{0}^{F}(\delta) .
\end{aligned}
$$

By deviating in one of the first $T$ periods, a manufacturer thus gets at most

$$
\max _{p}\left\{(1-\delta)[\pi(p, \underline{p})-\Pi(\underline{p})]-\delta \inf \left\{\frac{|\underline{p}-p|}{\bar{\varepsilon}}, 1\right\}\left(\Pi_{\tau+1}-\Pi_{0}\right)\right\} .
$$

Since $\Pi_{\tau}$ increases with $\tau$, the bigger gain from deviation is achieved for $\tau=0$; using the fact that $\delta\left(\Pi_{1}-\Pi_{0}\right)=(1-\delta)(\Pi(\underline{p})+v(\bar{\varepsilon})-k)$ by construction, there is thus no profitable deviation in the first $T$ periods if and only if

$$
\max _{p}\left\{\pi(p, \underline{p})-\Pi(\underline{p})+\inf \left\{\frac{|\underline{p}-p|}{\bar{\varepsilon}}, 1\right\}[\Pi(\underline{p})+v(\bar{\varepsilon})-k]\right\} \leq 0 .
$$

This condition is satisfied under (18). First note that if this was not the case, the optimal deviation would involve a price $p$ insufficiently different from $\underline{p}$ for being detected with probability $1(p \in[\underline{p}-\bar{\varepsilon}, \underline{p}+\bar{\varepsilon}])$, since the optimal deviation would otherwise be $q=\arg \max _{p} \pi(p, p)$ and would thus imply $\Delta(p)+v(\bar{\varepsilon})-k>0$, contradicting (18). Therefore, suppose there exists a price $p$ below $\underline{p}(p \in[\underline{p}-\bar{\varepsilon}, \underline{p}])$ such that

$$
\pi(p, \underline{p})-\Pi(\underline{p})+\frac{|\underline{p}-p|}{\bar{\varepsilon}}[\Pi(\underline{p})+v(\bar{\varepsilon})-k]>0 .
$$

Since the left-hand side is concave in $p$ and equal to 0 for $p=p$, its slope is necessarily negative for $p=p$, implying

$$
\bar{\varepsilon}[d-(2-\sigma) \underline{p}]+\Pi(\underline{p})+v(\bar{\varepsilon})-k>0,
$$


in contradiction with (18). A similar argument holds if the optimal deviation price $p$ is above $p$.

Lastly, note that (18) and (19) imply that $\underline{p}$ satisfies both (14) and (15) (with $\Pi_{F}=0$ ), and thus belongs to $I^{F}$. Therefore, $\hat{p} \in\left[\underline{p}, p_{0}^{F}(\delta)\right]$ also belongs to $I^{F}$ and, from the proof of Proof of Proposition 3.1, there is no profitable deviation from the punishment path in period $T$.

\section{Proof of proposition 4}

The same argument as before can be used to show that, along the equilibrium path generated by the best collusive strategy $\bar{s}$, the same price is charged in each period. Since $\underline{\Pi}=\Pi_{F}$, the equilibrium path is thus either of the form "charge an expected price $p^{F}$ without $R P M$ in each period", which yields $\Pi\left(p^{F}\right)+v(\bar{\varepsilon})-k$, or "charge $p^{R P M}$ with $R P M$ in each period", which yields $\Pi\left(p^{R P M}\right)-k$.

We will use the following lemma:

Fix $\bar{\varepsilon}$ and, for any price $p \in\left[p^{N}, p^{M}\right]$ such that $\Pi(p)<\Pi\left(p^{M}\right)-v(\bar{\varepsilon})$, define $q(p)$ as the lower solution to

$$
\Pi(q)=\Pi(p)+v(\bar{\varepsilon})
$$

and

$$
\phi(p) \equiv \bar{\varepsilon}((2-\sigma) p-d)-\left(\frac{(2-\sigma) q(p)-d}{2}\right)^{2}-v(\bar{\varepsilon}) .
$$

Then, if $\max _{p^{N}<p<p^{M}} \phi(p)>0$, there exists a range of values of the discount factor for which $R P M$ is necessarily used along the equilibrium path of the best collusive FSE.

For any price $p \in\left[p^{N}, p^{M}\right]$ such that $\Pi(p)<\Pi\left(p^{M}\right)-v(\bar{\varepsilon})$, define $\delta(p)$ as the unique solution to

$$
\bar{\varepsilon}[(2-\sigma) p-d]=\frac{\delta}{1-\delta}[\Pi(p)+v(\bar{\varepsilon})-k] .
$$

We first show that if $\phi(p)>0$ for a price $p \in\left[p^{N}, p^{M}\right]$, then $R P M$ is necessarily used along the equilibrium path of the best collusive FSE when $\delta=\delta(p)$. Note first that for $\delta=\delta(p), p^{F} \leq p$ since by construction (6) is binding at $p$. Second, (23) and $\phi(p)>0$ imply (using $\Delta(p)-\Pi(p)=$ $\left.\left(\frac{(2-\sigma) p-d}{2}\right)^{2}\right)$

$$
\begin{aligned}
\Delta(q(p))+v(\bar{\varepsilon})-\Pi(q(p)) & <\frac{\delta}{1-\delta}[\Pi(p)+v(\bar{\varepsilon})-k] \\
& =\frac{\delta}{1-\delta}[\Pi(q(p))-k]
\end{aligned}
$$


and thus $q(p)$ satisfies (7). Therefore, a price slightly above $q(p)$ is feasible with $R P M$ and more profitable than $p$ (and thus $p^{F}$ ) ${ }^{25}$ without $R P M$.

To complete the proof, it suffices to note that $\delta(p)$ is increasing in $p$. Therefore, whenever $\max _{p^{N}<p<p^{M}} \phi(p)>0$, there exists a range of values $p$ for which $\phi(p)>0$ ( $\phi$ is concave, so that this range is actually an interval) and, therefore, a range of values of the discount factor for which $R P M$ is necessarily used along the best collusive equilibrium path.

It is straightforward to check that the function $\phi(p)$ is concave and reaches its maximum for $p$ characterized by the first-order condition:

$$
p^{M}-p=\frac{2 \bar{\varepsilon}}{2-\sigma} \frac{p^{M}-q(p)}{q(p)-p^{N}} .
$$

We now show that when $\bar{\varepsilon} / d$ is small enough, the price $p \in\left[p^{N}, p^{M}\right]$ defined by (24) satisfies $\phi(p)>0$. Defining $\eta=\bar{\varepsilon} / d$ and $x, y, \lambda$ and $\mu$ by

$$
\begin{aligned}
p & =x p^{N}+(1-x) p^{M}, \\
q(p) & =y p^{N}+(1-y) p^{M}, \\
\lambda & =\frac{\sigma}{2(1-\sigma)} \\
\mu & =\frac{2-\sigma}{\sigma} \sqrt{\frac{1-\sigma}{3}}
\end{aligned}
$$

conditions (21) and (24) become

$$
\begin{aligned}
x^{2} & =y^{2}+\mu \eta^{2}, \\
2 \eta & =\lambda(1-y) \frac{x}{y},
\end{aligned}
$$

Conditions (25) and (26) define $x$ and $y$ as a function of $\eta$, and, combined together, yield

$$
2 \eta=\lambda(1-y) \sqrt{1+\mu \frac{\eta^{2}}{y^{2}}} .
$$

Since the right-hand side of this equation is a decreasing function of $y$ for $y>0$ and equals 0 for $y=1$, there is a one-to-one relationship between $\eta$

\footnotetext{
${ }^{25}$ We already show that $p^{F} \leq p$, which is sufficient to conclude; the fact that (7) is satisfied at $q(p)$ however implies that the weaker constraint (5) is also satisfied at $q(p)$ and thus at $p<q(p)$. Therefore, $p^{F}=p$.
} 
and $y$, and $y$ tends to 1 as $\eta$ tends to 0 . Condition (25) then also implies that $x$ tends to 1 as $\eta$ gets to 0 and, moreover, the first-order approximation yields, for $\eta$ small:

$$
x \sim y \sim 1-\frac{2}{\lambda} \eta
$$

Finally, for $x$ and $y$ satisfying (25) and $(26), \phi(p)$ can be written as

$$
\left(\lambda \frac{1-x}{\eta}+\mu \frac{\eta^{2}}{x^{2}}-\frac{13}{12}\right) \bar{\varepsilon}^{2}
$$

and

$$
\lim _{\eta \rightarrow 0}\left(\lambda \frac{1-x}{\eta}+\mu \frac{\eta^{2}}{x^{2}}-\frac{13}{12}\right)=\frac{11}{12}>0
$$

Therefore, for $\eta=\bar{\varepsilon} / d$ small enough, there exist $x$ and $y$, solution to (25) and (26), which satisfy $0<x<y<1$ and for which $\phi>0$.

The final point is to show that the analysis is compatible with the assumption $\Pi_{F}=0$. To see this, notice that the interval of prices $p$ such that $\phi(p)>0$ is independent of $\delta$ and $k$. Let us fix all parameters except these two and choose a price $p$ in the relevant interval. Then (23) defines an increasing relationship between $k$ and $\delta$. As $k$ converges to $\Pi\left(p^{N}\right)+v(\bar{\varepsilon}), \delta$ converges to some positive limit. Choose $\hat{\delta}$ strictly smaller than this limit, and let $\hat{k}$ be the corresponding fixed cost defined in proposition (4). Then for $k$ high enough, $\delta$ defined by (23) is larger than $\hat{\delta}$ while $k>\hat{k}$. Thus $\Pi_{F}=0$ and $R P M$ is used in equilibrium.

\section{Proof of Proposition 5}

As before let $\Pi_{0}^{F}(\delta)$ be the maximal profit that could be sustained if $\Pi_{F}=0$. When $\bar{\varepsilon} / d$ is small enough, there exists $\widetilde{p}$ and $\underline{p}$ such that $\underline{p}<\widetilde{p}<p^{N}$ and

$$
\Pi(\widetilde{p})=\Delta(\underline{p}),
$$

and

$$
\bar{\varepsilon}[d-(2-\sigma) \widetilde{p}]>\Delta(\underline{p})+v(\bar{\varepsilon})-\Pi(\underline{p}) .
$$

Consider the following system: 


$$
\begin{gathered}
\Pi(\widetilde{p})=\Delta(\underline{p}), \\
\frac{\bar{\varepsilon}}{2}[d-(2-\sigma) \widetilde{p}]=\Delta(\underline{p})-\Pi(\underline{p}) .
\end{gathered}
$$

Equation (29) defines $\underline{p}$ as an increasing function of $\widetilde{p}$ with $\underline{p}=p^{N}$ at $\widetilde{p}=p^{N}$ and

$$
\left.\frac{d \underline{p}}{d \widetilde{p}}\right|_{\widetilde{p}=p^{N}}=1
$$

Equation (30) defines in turn $\widetilde{p}$ as a function of $\bar{\varepsilon}$, with value $p^{N}$ at $\bar{\varepsilon}=0$ and

$$
\left.\frac{d \widetilde{p}}{d \bar{\varepsilon}}\right|_{\bar{\varepsilon}=0}=-\frac{2}{2-\sigma} .
$$

Choose then $\bar{\varepsilon}$ small ${ }^{26}$ and $\widetilde{p}$ and $\underline{p}$ defined by (29) and (30). Then $\underline{p}<\widetilde{p}<p^{N}$ and

$$
\frac{\bar{\varepsilon}}{2}[d-(2-\sigma) \widetilde{p}] \sim \bar{\varepsilon}^{2}>v(\bar{\varepsilon})=\frac{\bar{\varepsilon}^{2}}{12} .
$$

Therefore

$$
\bar{\varepsilon}[d-(2-\sigma) \widetilde{p}]-v(\bar{\varepsilon})>\frac{\bar{\varepsilon}}{2}[d-(2-\sigma) \widetilde{p}]=\Delta(\underline{p})-\Pi(\underline{p}) .
$$

Suppose now that $\bar{\varepsilon} / d$ is indeed "small", and fix $\delta$ and $k$ such that, for $\underline{p}$ and $\widetilde{p}$ defined as in the above lemma,

$$
\begin{aligned}
\Pi(\widetilde{p})+v(\bar{\varepsilon})-k & =\Delta(\underline{p})+v(\bar{\varepsilon})-k=0, \\
\frac{\delta}{1-\delta} \Pi_{0}^{F}(\delta) & =\Delta(\underline{p})+v(\bar{\varepsilon})-\Pi(\underline{p})<\bar{\varepsilon}[d-(2-\sigma) \widetilde{p}] .
\end{aligned}
$$

Consider first the case without $R P M$ and suppose that $\Pi_{F}=0$. Then the maximal profit is $\Pi_{0}^{F}(\delta)$. But since by construction $\bar{\varepsilon}[d-(2-\sigma) \widetilde{p}]>$ $\frac{\delta}{1-\delta}\left[\Pi_{0}^{F}(\delta)-0\right], \widetilde{p} \notin I_{F}$; similarly, for any price $p$ further away from $p^{N}$,

$$
\bar{\varepsilon}|d-(2-\sigma) p|=\bar{\varepsilon}(2-\sigma)\left|p^{N}-p\right|>(2-\sigma) \bar{\varepsilon}\left|p^{N}-\widetilde{p}\right|>\frac{\delta}{1-\delta} \Pi_{0}^{F}(\delta),
$$

\footnotetext{
${ }^{26}$ While we show here that for any given $d$ a solution exists for $\bar{\varepsilon}$ "small enough", it should be clear that the same argument applies whenever $\bar{\varepsilon} / d$ is "small' $(\widetilde{p} / d$ and $\underline{p} / d$ are the relevant variables).
} 
and thus $p \notin I_{F}$. Therefore, all prices in $I_{F}$ are closer to $p^{N}$ than $\widetilde{p}$ and thus generate a strictly positive profit. ${ }^{27}$ This implies

$$
\Pi_{F} \geq \inf _{p \in I_{F}}\{\Pi(p)+v(\bar{\varepsilon})-k\}>0
$$

a contradiction.

We now turn to the case where $R P M$ is allowed and consider the following equilibrium: play $p$ with $R P M$ for one period, then play $s^{F}$; start again if a deviation occurs. The profit is

$$
(1-\delta)[\Pi(\underline{p})-k]+\delta \Pi_{0}^{F}(\delta)=0 .
$$

The incentive compatibility condition is then

$$
\Delta(\underline{p})+v(\bar{\varepsilon})-\Pi(\underline{p}) \leq \frac{\delta}{1-\delta} \Pi_{0}^{F}(\delta),
$$

which is trivially verified. Therefore $\underline{\Pi}=0$ is an equilibrium profit as well as $\Pi_{0}^{F}(\delta)$.

\section{E Nonlinear tariffs and retailers' arbitrage}

We now assume that there are $n$ locations $k=1, \ldots, n$, in which each producer $i=1,2$ has a single retailer facing a local shock $\varepsilon_{i k}$ on demand. The framework is the same as in the core model, except that: i) each producer $i$ can offer each retailer $k$ a menu of nonlinear tariffs $T_{i k}$; ii) retailers can coordinate on quantity exchanges, transfers and retail prices so as to take advantage of any arbitrage opportunity offered by wholesale tariffs; iii) there is a common shock on the demand faced by all retailers of a given product. The demand of a retailer is then

$$
d_{i}+\varepsilon_{i k}-p_{i k}+\sigma p_{j k}
$$

where $d_{i}$ and $\varepsilon_{i k}$ are independent, with respective means $d$ and $0\left(\varepsilon_{i k}\right.$ and $\varepsilon_{i k^{\prime}}$ can be correlated). For the sake of tractability, we will assume that all retailers of a same producer $i$ share the information regarding the local shocks $\varepsilon_{i}=\left(\varepsilon_{i k}\right)_{k=1, \ldots, n}$ when deciding on inter-retailer trade and prices, but none of them observes the aggregate shock $d_{i}$ at this stage. ${ }^{28}$ Then,

\footnotetext{
${ }^{27}$ By construction, $\Pi(\widetilde{p})+v(\bar{\varepsilon})-k=0$; the conclusion follows from the fact that $\Pi(p)$ is quadratic and reaches its peak for a price $p$ higher than $p^{N}$.

${ }^{28}$ The reason for introducing an aggregate shock on demand is to limit the information contained in quantities, see below.
} 
given the menus $T_{i k}$ and the stochastic distribution of the rival's retail prices $\left(p_{j k}\right)_{k=1, \ldots, n}$, where each price $p_{j k}$ a priori depends on the realization of all shocks $\varepsilon_{j} \equiv\left(\varepsilon_{j h}\right)_{h=1, \ldots, n}$, each retailer will select a tariff $t_{i k}$, a price $p_{i k}$ and an internal quantity transfer ${ }^{29} \delta_{i k}$ solution to:

$\max _{\left(t_{i k}(.), p_{i k}, \delta_{i k}\right)_{k}} E\left[\sum_{k} p_{i k}\left(d_{i}+\varepsilon_{i k}-p_{i k}+\sigma p_{j k}\left(\varepsilon_{j}\right)\right)-t_{i k}\left(d_{i}+\varepsilon_{i k}-p_{i k}+\sigma p_{j k}\left(\varepsilon_{j}\right)+\delta_{i k}\right) \mid \varepsilon_{i}\right]$
$t_{i k}(.) \in T_{i k}$,
$\sum_{k} \delta_{i k}=0$.

Defining

$$
\begin{aligned}
p_{j k}^{e} & =E\left[p_{j k}\left(\varepsilon_{j}\right)\right] \\
\bar{q}_{i k} & =d+\varepsilon_{i k}-p_{i k}+\sigma p_{j k}^{e}+\delta_{i k} \\
\hat{t}_{i k}(q) & =E\left[t_{i k}\left(q+d_{i}-d+\sigma\left(p_{j k}\left(\varepsilon_{j}\right)-p_{j k}^{e}\right)\right)\right],
\end{aligned}
$$

and denoting by $\hat{T}_{i k}$ the set of "tariffs" obtained by applying the above transformation to the original tariffs $t_{i k}$ in $T_{i k}$, the above program can be rewritten as

$$
\begin{array}{cc}
\max _{\left(\hat{t}_{i k}(.), p_{i k}, \bar{q}_{i k}\right)_{k}} & \sum_{k}\left[p_{i k}\left(d+\varepsilon_{i k}-p_{i k}+\sigma p_{j k}^{e}\right)-\hat{t}_{i k}\left(\bar{q}_{i k}\right)\right] \\
\hat{t}_{i k}(.) \in \hat{T}_{i k}, \\
\sum_{k}\left(d+\varepsilon_{i k}-p_{i k}+\sigma p_{j k}^{e}\right)=\sum_{k} \bar{q}_{i k} .
\end{array}
$$

It is useful to first characterize the distribution of retail prices, $\left(p_{i k}\right)_{k=1 \ldots ., n}$, for a given total "expected quantity" $Q_{i}=\sum_{k} \bar{q}_{i k}$; those prices are solution to:

$$
\begin{array}{cc}
\max _{\left(p_{i k}\right)_{k}} & \sum_{k} p_{i k}\left(d+\varepsilon_{i k}+\sigma p_{j k}^{e}-p_{i k}\right) \\
\sum_{k}\left(d+\varepsilon_{i k}+\sigma p_{j k}^{e}-p_{i k}\right)=Q_{i}
\end{array}
$$

Denoting by $\lambda_{i}$ the Lagrangian multiplier associated with the constraint, the necessary and sufficient optimality conditions are

$$
\begin{aligned}
d+\varepsilon_{i k}+\sigma p_{j k}^{e}-2 p_{i k}+\lambda_{i} & =0, \\
\sum_{k}\left(d+\varepsilon_{i k}-p_{i k}+\sigma p_{j k}^{e}\right) & =Q_{i},
\end{aligned}
$$

\footnotetext{
${ }^{29}$ Each retailer $k$ can transfer a quantity $\hat{\delta}_{i k k^{\prime}}$ to any other retailer $k^{\prime}$ of the same producer $i$; however, only the overall transfer $\delta_{i k}=\Sigma_{k^{\prime}} \hat{\delta}_{i k k^{\prime}}$ matters for our purpose. Note that we do not allow retailers of one product to make quantity transfers contingent on the other retailers' ex post price, in order to avoid introducing interbrand links in the contractual relations.
} 
and thus, eliminating $\lambda_{i}$ :

$$
p_{i k}=d-\frac{Q_{i}}{n}+\frac{1}{2}\left(\varepsilon_{i k}+\sum_{h} \varepsilon_{i h}\right)+\frac{\sigma}{2}\left(p_{j k}^{e}+\sum_{h} p_{j h}^{e}\right) .
$$

Using those conditions, the previous retailers' program can be rewritten as (ignoring terms that do not depend on the decision variables)

$$
\begin{gathered}
\max _{\left(\hat{t}_{i k}(.), Q_{i}, \bar{q}_{i k}\right)_{k}}\left[d+\frac{1}{n}\left(\sum_{k} \varepsilon_{i k}+\sigma \sum_{k} p_{j k}^{e}-Q_{i}\right)\right] Q_{i}-\hat{t}_{i k}\left(\bar{q}_{i k}\right) \\
\hat{t}_{i k}(.) \in \hat{T}_{i k}, \\
\sum_{k} \bar{q}_{i k}=Q_{i} .
\end{gathered}
$$

which depends on the realization of the local shocks $\left(\varepsilon_{i k}\right)_{k=1, \ldots, n}$ only through the aggregate shock $\bar{\varepsilon}_{i} \equiv \sum_{k} \varepsilon_{i k}$. Therefore, $Q_{i}=Q_{i}\left(\bar{\varepsilon}_{i}\right)$ and the retail prices are of the form:

$$
p_{i k}=\hat{p}_{i k}\left(\bar{\varepsilon}_{i}\right)+\frac{\varepsilon_{i k}}{2}
$$

where

$$
\hat{p}_{i k}\left(\bar{\varepsilon}_{i}\right) \equiv d+\frac{1}{2} \bar{\varepsilon}_{i}-\frac{1}{n} Q_{i}\left(\bar{\varepsilon}_{i}\right)+\frac{\sigma}{2}\left(p_{j k}^{e}+\sum_{h} p_{j h}^{e}\right)
$$

Therefore,

$$
\begin{aligned}
\operatorname{Var}\left[p_{i k}\right] & =\operatorname{Var}\left[\hat{p}_{i k}\left(\bar{\varepsilon}_{i}\right)+\frac{\varepsilon_{i k}}{2}\right] \\
& =E\left[\frac{\left(\varepsilon_{i k}\right)^{2}}{4}+\varepsilon_{i k} \hat{p}_{i k}\left(\bar{\varepsilon}_{i}\right)+\hat{p}_{i k}^{2}\left(\bar{\varepsilon}_{i}\right)\right] \\
& =\frac{1}{4} \operatorname{Var}\left[\varepsilon_{i k}\right]+E\left[\varepsilon_{i k} \hat{p}_{i k}\left(\bar{\varepsilon}_{i}\right)+\hat{p}_{i k}^{2}\left(\bar{\varepsilon}_{i}\right)\right] .
\end{aligned}
$$

We now compute a lower bound of this variance by minimizing

$$
E\left[\varepsilon_{i k} f\left(\bar{\varepsilon}_{i}\right)+f^{2}\left(\bar{\varepsilon}_{i}\right)\right]=E\left[E\left[\varepsilon_{i k} \mid \bar{\varepsilon}_{i}\right] f\left(\bar{\varepsilon}_{i}\right)+f^{2}\left(\bar{\varepsilon}_{i}\right)\right]
$$

point by point, which yields:

$$
E\left[\varepsilon_{i k} \mid \bar{\varepsilon}_{i}\right]+2 f\left(\bar{\varepsilon}_{i}\right)=0,
$$


or $f\left(\bar{\varepsilon}_{i}\right)=-\frac{1}{2} E\left[\varepsilon_{i k} \mid \bar{\varepsilon}_{i}\right]$. Hence, a lower bound of the above variance is given by

$$
\begin{aligned}
& \frac{1}{4} \operatorname{Var}\left[\varepsilon_{i k}\right]-\frac{1}{2} E\left[\varepsilon_{i k} E_{\varepsilon_{i}}\left[\varepsilon_{i k} \mid \bar{\varepsilon}_{i}\right]\right]+\frac{1}{4}\left(E\left[\varepsilon_{i k} \mid \bar{\varepsilon}_{i}\right]\right)^{2} \\
= & \frac{1}{4}\left\{\operatorname{Var}\left[\varepsilon_{i k}\right]-\operatorname{Var}\left[E_{\varepsilon_{i}}\left[\varepsilon_{i k} \mid \bar{\varepsilon}_{i}\right]\right]\right\} \\
= & \frac{1}{4} E\left[\operatorname{Var}\left[\varepsilon_{i k} \mid \bar{\varepsilon}_{i}\right]\right] .
\end{aligned}
$$

When local shocks are independently and identically distributed, this minimal variance increases with the number or retailers $n$ and boils down in the limit ( $n$ very large) to $\operatorname{Var}\left[\varepsilon_{i k}\right] / 4$, the variance generated by two-part tariffs.

\section{Remark: Information contained in quantities}

In the case of a single market, observing the quantity sold is uninformative since all the information is already contained in the two retail prices. In contrast, in a multi-market context where only a few prices are observed, quantities may convey useful information. However in the presence of expost aggregate demand shocks, this information is not sufficient to detect deviations for sure, even with a very large number of markets. To see this, assume that a manufacturer observes all of its retailers' prices and the quantity bought by each of them, but not the rival's retail prices. Given the contracts offered, manufacturer $i$ can compute the retailers' pricing policy $p_{i k}\left(\varepsilon_{i}\right)=\hat{p}_{i k}\left(\bar{\varepsilon}_{i}\right)+\varepsilon_{i k} / 2$. Observing all prices $p_{i k}$, the manufacturer can infer ex-post $\bar{\varepsilon}_{i}$ (since $\Sigma_{k} p_{i k}\left(\varepsilon_{i}\right)$ only depends on $\bar{\varepsilon}_{i}$ ) and thus all individual shocks $\varepsilon_{i k}$. Therefore its retailers' prices fully inform the manufacturer about its own retailers' information. We now show that it however provides only an imperfect information about the rival's prices.

The demand eventually addressed by retailer $i k$ to manufacturer $i$ is

$$
q_{i k}=d_{i}+\varepsilon_{i k}-p_{i k}+\sigma p_{j k}+\delta_{i k}\left(\varepsilon_{i}\right),
$$

where $p_{i k}$ is observed, and both $\varepsilon_{i k}$ and $\delta_{i k}$ can be inferred, by the manufacturer. Therefore, observing both its retailers' prices and quantities informs manufacturer $i$ on

$$
d_{i}+\sigma p_{j k} .
$$

Building on the above analysis, the retail prices $p_{j k}$ will take the form:

$$
p_{j k}=\hat{p}_{j}\left(\bar{\varepsilon}_{j}\right)+\frac{\varepsilon_{j k}}{2}
$$


where $\hat{p}_{j}\left(\bar{\varepsilon}_{j}\right)$ depends on the contracts offered by the rival. Therefore, the only relevant information concerning the opponents actions contained in $d_{i}+\sigma p_{j k}$ is about $\hat{p}_{j}\left(\bar{\varepsilon}_{j}\right)$, and the maximal useful information is thus contained in the mean:

$$
\frac{1}{n} \Sigma_{k}\left(d_{i}+\sigma p_{j k}\right)=d_{i}+\sigma \hat{p}\left(\bar{\varepsilon}_{j}\right)+\sigma \frac{\bar{\varepsilon}_{j}}{2 n} .
$$

Since $d_{i}$ is independent from $\bar{\varepsilon}_{j}$, this is only a garbled information on the opponents pricing strategy. 